\title{
Synergistic lethality between PARP-trapping and alantolactone-induced oxidative DNA damage in homologous recombination-proficient cancer cells
}

\author{
Hongge Wang ${ }^{1} \cdot$ Shan Zhang $^{1} \cdot$ Liyan Song $^{1} \cdot$ Meng Qu $^{1} \cdot$ Zhihua Zou $^{1}$
}

Received: 21 August 2019 / Revised: 21 January 2020 / Accepted: 24 January 2020 / Published online: 6 February 2020

(c) The Author(s) 2020. This article is published with open access

\begin{abstract}
PARP1 and PARP2 play critical roles in regulating DNA repair and PARP inhibitors have been approved for the treatment of BRCA1/2-mutated ovarian and breast cancers. It has long been known that PARP inhibition sensitizes cancer cells to DNAdamaging cytotoxic agents independent of BRCA status, however, clinical use of PARP inhibitors in combination with DNAdamaging chemotherapy is limited by the more-than-additive cytotoxicity. The natural compound alantolactone (ATL) inhibits the thioredoxin reductase to induce ROS accumulation and oxidative DNA damage selectively in cancer cells. Here, we showed that nontoxic doses of ATL markedly synergized with the PARP inhibitor olaparib to result in synthetic lethality irrespective of homologous recombination status. Synergistic cytotoxicity was seen in cancer but not noncancerous cells and was reduced by the ROS inhibitor NAC or knockdown of OGG1, demonstrating that the cytotoxicity resulted from the repair of ATL-induced oxidative DNA damage. PARP1 knockdown suppressed the synergistic lethality and olaparib was much more toxic than veliparib when combined with ATL, suggesting PARP-trapping as the primary inducer of cytotoxicity. Consistently, combined use of ATL and olaparib caused intense signs of replication stress and formation of double strand DNA breaks, leading to $S$ and $G_{2}$ arrest followed by apoptosis. In vivo, the combination effectively induced regression of tumor xenografts, while either agent alone had no effect. Hence, PARP trapping combined with specific pro-oxidative agents may provide safe and effective ways to broaden the therapeutic potential of PARP inhibitors.
\end{abstract}

\section{Introduction}

Cancer cells exhibit chronic replication stress, accumulate DNA damage and are highly dependent on compensatory DNA damage response (DDR) functions for survival. Thus, targeting DNA repair and/or DDR has emerged as a promising anticancer approach $[1,2]$. Poly(ADP-ribose) polymerase 1 (PARP1), and to a lesser extent PARP2, play critical and overlapping roles in the major DNA repair pathways and in the maintenance of genomic

Supplementary information The online version of this article (https:// doi.org/10.1038/s41388-020-1191-x) contains supplementary material, which is available to authorized users.

Zhihua Zou

zouzh@jlu.edu.cn

1 Department of Cell Biology and Biophysics, National Engineering Laboratory for AIDS Vaccine, Key Laboratory for Molecular Enzymology and Engineering of the Ministry of Education, School of Life Sciences, Jilin University, Changchun, China stability [3, 4]. They detect single strand DNA breaks (SSB) and initiate SSB repair (SSBR) [5]; in addition, they are required for a subset of base excision repair (BER) [6] and perform regulatory roles in double strand DNA break (DSB) repair [4]. Importantly, they play critical roles in the stabilization and restart of stalled DNA replication forks [7-9]. Thus, when the activity of PARP1/2 is inhibited, unrepaired SSBs and stalled replication forks accumulate, resulting in collapse of replication forks and generation of DSBs during DNA replication [10], which are repaired by HR-mediated repair (HRR) pathways [3, 4]. However, BRCA1 or BRCA2-null cancer cells are deficient in HR and the problems caused by PARP inhibition become lethal even in the absence of exogenous genotoxic stress [11-13]. These observations have greatly accelerated the development of PARP inhibitors (PARPis) [14, 15]. Several PARPis are now approved for the treatment of BRCA1/2mutated ovarian and breast cancers [16]. However, as most cancers are HR-proficient, the clinical potential of PARPi as monotherapy is very limited. 
It has long been known that inhibition of PARP1/2 sensitizes cancer cells to ionizing radiation and DNA-damaging genotoxic agents independent of $\operatorname{HR}$ status [17, 18]. In addition, preclinical and clinical studies have shown that PARP-1 activity in cancer cells is critical for the establishment of resistance to genotoxic therapies [19, 20], suggesting that there is a real opportunity to combine PARPi with chemotherapy and radiotherapy [21, 22]. However, clinical trials designed to test the use of PARPis in combination with chemo/radiotherapy have been unsuccessful, largely due to unexpected more-than-additive side-effects [16].

Increased generation of reactive oxygen species (ROS) is another distinctive feature associated with oncogenic transformation which renders cancer cells vulnerable to further oxidative insult [23]. Thus, agents that weaken the antioxidant systems or promote generation of ROS can induce oxidative DNA damage selectively in cancer cells [24-27]. PARP1/2 are required for the repair of oxidative DNA lesions [28-30] and it has been shown that PARP inhibition sensitizes cells to oxidative stress [31-33], raising the possibility of using PARPis in combination with prooxidative agents to yield cancer-specific synergistic lethality. The natural compound alantolactone (ATL) increases cellular ROS levels by inhibiting the thioredoxin reductase (TrxR) [34-37]. We and others have shown that ATLinduced ROS elevation resulted in extensive DNA damage selectively in cancer cells $[37,38]$. Here we showed that PARP-trapping caused by the PARPi olaparib markedly synergized with non-toxic doses of ATL to result in cancerspecific lethality and co-administration of sublethal doses of olaparib and ATL effectively induced regression of tumor xenografts in vivo. These studies support further exploration of synergistic lethality between PARP trapping and specific pro-oxidative agents in order to use PARP inhibitors in the treatment of cancer irrespective of HR status.

\section{Results}

\section{ATL-induced oxidative DNA damage activates PARP in cancer cells}

Tumor cell toxicity is a well-known property of ATL, but the effective concentrations reported in the literature were very high, with $\mathrm{IC}_{50}$ values ranging from 20 to $60 \mu \mathrm{M}$ in various solid tumor cell lines [38-40]. In agreement with the literature, we found $10 \mu \mathrm{M}$ ATL had no significant impact on the clonogenic growth of many human cancer cell lines (Fig. S1A), nevertheless, it induced a marked increase in ROS levels. Within $30 \mathrm{~min}$ of treatment, ROS levels increased by 10 -fold in the PC-3 prostate cancer cells (Fig. 1a, b) and remained unchanged until the $12 \mathrm{~h}$ time point (Fig. 1b). A rapid increase in ROS levels was also induced by $10 \mu \mathrm{M}$ ATL in the SW480 colorectal and A549 lung carcinoma (Fig. S1B) as well as many other cancer cell lines (Fig. S1C). Lowering the concentrations of ATL to as low as $0.625 \mu \mathrm{M}$ could still induce a significant increase in ROS levels, and the ROS increase induced by the nontoxic concentrations of ATL in the PC-3 and SW480 cancer cells exhibited optimal dose-dependency (Fig. S1D). In contrast, similar treatment caused no significant ROS elevation in the noncancerous NCM460 normal colon (Fig. 1c, d), BEAS2B bronchial and HEK293 embryonic kidney epithelial cell lines (Fig. S1C). The ROS inhibitor $N$-acetyl-L-cysteine (NAC) efficiently blocked the ATL-induced ROS increase in the cancer cells (Fig. 1a, b and Fig. S1B). Cancer cells characteristically have higher oxidative pressure and upregulate antioxidant systems to combat the toxicity of excessive levels of ROS [26, 27]. As ATL is known to inhibit thioredoxin reductase (TrxR) [34], our results suggested that the thioredoxin antioxidant system likely plays critical roles in most cancer cells. On the other hand, normal cells may better tolerate TrxR inhibition owing to their normal basal ROS output.

At elevated levels, ROS can cause SSBs and oxidize nucleobases in DNA/RNA and free nucleotides [41, 42]. We found that the ATL-induced ROS elevation in the PC-3, SW480 and A549 cancer cells was followed by accumulation of cellular 8-oxoguanine (8-oxoG) (Fig. 1e, f and Fig. S2A) and an increase in DNA strand breaks as revealed by the alkaline comet assay (Fig. 1g, h and Fig. S2B). Both effects were reversed by NAC (Fig. 1e-h and Fig. S2A-B), suggesting that endogenous oxidative pressure in cancer cells was responsible for these oxidative DNA lesions following inhibition of the thioredoxin antioxidant system by ATL.

PARP1/2 sense and bind SSBs produced directly or as intermediates of BER repair of certain types of damaged DNA bases [3]. This stimulates the catalytic activity of PARP1/2, which results in rapid synthesis of poly(ADPribose) (PAR) chains (PARylation) on proteins at sites of SSB. Consistent with the increase in cellular 8-oxoG levels and DNA strand breaks, PAR levels increased in a timedependent manner in ATL-treated cancer but not the NCM460 and BEAS-2B cells (Fig. 1i, j and Fig. S2C). NAC treatment reduced the accumulation of PAR in the cancer cells (Fig. 1j and Fig. S2C), correlating the PARylation with oxidative DNA damage. These results revealed that a nontoxic dose of ATL caused oxidative DNA damage specifically in cancer cells which activated PARP-mediated DNA repair activity.

\section{ATL sensitizes HR-proficient cancer cells to olaparib}

The increase in PAR levels prompted us to ask if nontoxic doses of ATL could sensitize cancer cells to PARPi. We first assessed the cytotoxicity of the PARPi olaparib in the 
Fig. 1 A nontoxic dose of ATL induces oxidative DNA

damage and activates PARP in cancer cells. The PC- 3 prostate cancer and NCM460 normal colon epithelial cells, with or without $1 \mathrm{~h}$ of preincubation in $10 \mathrm{mM}$ NAC, were treated by $10 \mu \mathrm{M}$ ATL or vehicle control for the indicated times.

a, b Measurement of ROS in PC-3 cells by flow cytometry. Data from three independent experiments were presented as mean $\pm \mathrm{SD}$. c, $\mathbf{d}$ Measurement of ROS in NCM460 cells by flow cytometry.

e, f Immunofluorescent staining of cellular 8-oxoG by $\mathrm{Cy} 3-$ conjugated avidin. PC-3 cells were treated by $10 \mu \mathrm{M}$ ATL for $12 \mathrm{~h}$ (scale bar: $10 \mu \mathrm{m}$ ). Nuclear 8-oxoG intensity was measured using the Image J software and the data were processed by the Prism software. g Representative images of alkaline comet assay. PC-3 cells were treated by vehicle control or $10 \mu \mathrm{M}$ ATL for $12 \mathrm{~h}$. $\mathbf{h}$ The tail moment was defined as percentage of tail DNA $\times$ tail length, quantified using the TriTek CometScore software. i Immunofluorescence staining for PAR foci in PC-3 cells treated by $10 \mu \mathrm{M}$ ATL for $12 \mathrm{~h}$. DNA was counterstained with DAPI (scale bar: $5 \mu \mathrm{m}$ ).

j Western blot analysis of PAR in PC-3 cells. Ten micrometer ATL resulted in a timedependent increase in PAR levels which was blocked by NAC. $n$.s. not significant, $* * p<$ $0.01, * * * p<0.001$ vs. vehicle control.
A
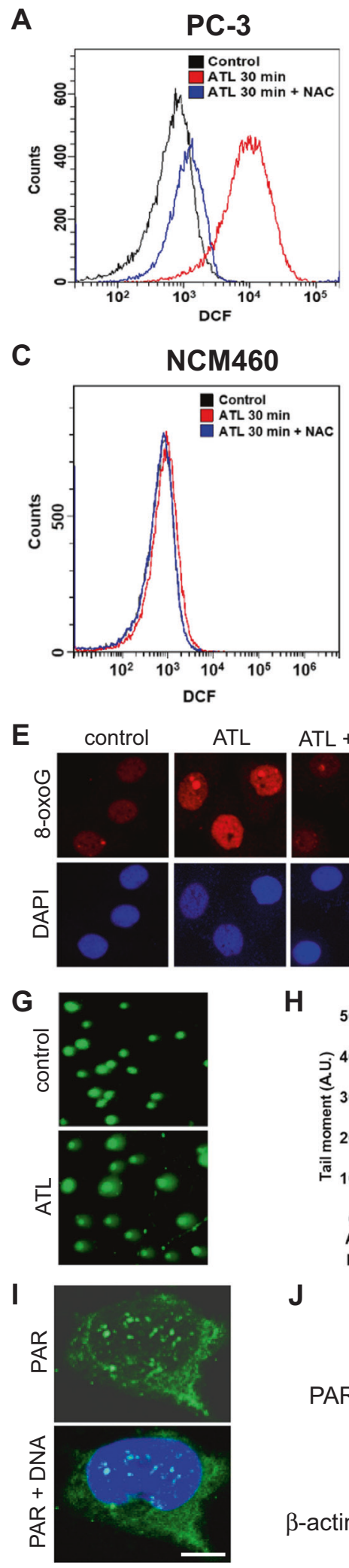
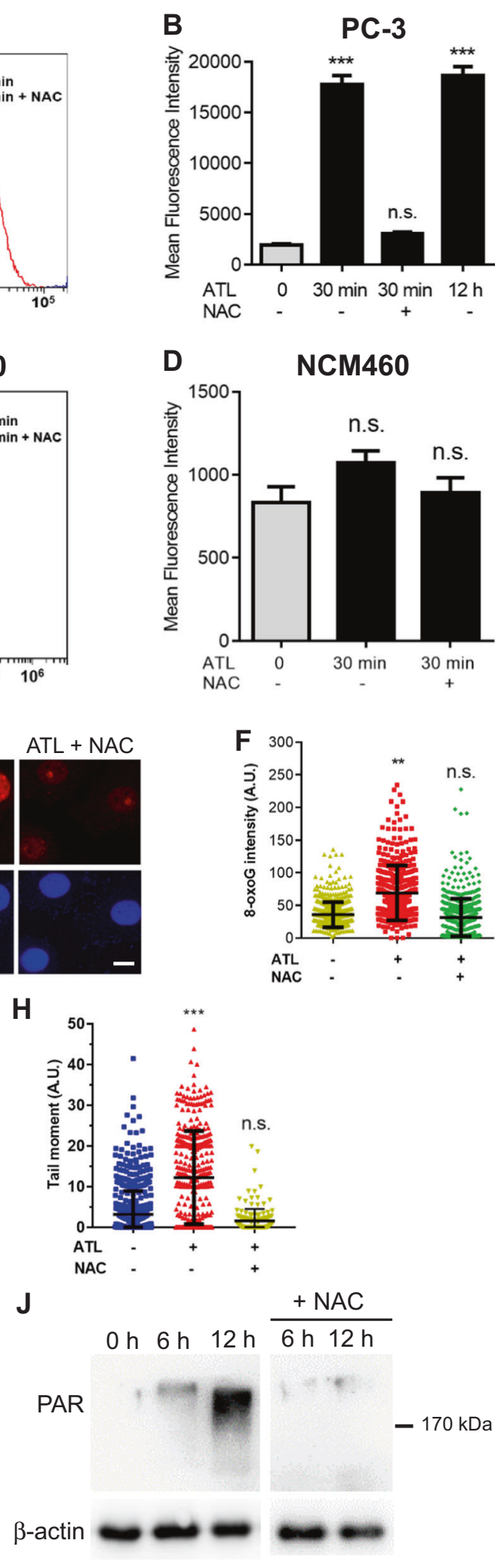

PC-3, A549, and SW480 cancer cell lines and found the $\mathrm{IC}_{50}$ to be $46.07,35.69$, and $91.06 \mu \mathrm{M}$, respectively (Fig. S3A). Consistently, both $10 \mu \mathrm{M}$ ATL and $10 \mu \mathrm{M}$ olaparib did not affect the clonogenic growth of these cancer cell lines but remarkably, the combination of $10 \mu \mathrm{M}$ ATL and $10 \mu \mathrm{M}$ olaparib completely inhibited their 
clonogenic survival (Fig. 2a, b and Fig. S3B). Similarly, MTT proliferation assay showed that, in the presence of $10 \mu \mathrm{M}$ ATL, olaparib dose-dependently inhibited the viability of the PC-3, A549, and SW480 cancer cells while olaparib monotherapy was nontoxic (Fig. 2c and Fig. S3C). In stark contrast, the clonogenicity of the noncancerous NCM460 (Fig. 2a, b) and BEAS-2B (Fig. S3B) cell lines was not affected by the combination of $10 \mu \mathrm{M}$ ATL and $10 \mu \mathrm{M}$ olaparib.

To evaluate the nature of the additive cytotoxicity between ATL and olaparib, we determined the combination index (CI) by the Chou-Talalay method using the CompuSyn software [43]. The CI values for the combinations between $10 \mu \mathrm{M}$ ATL and a series of olaparib concentrations indicated synergism $(\mathrm{CI}<1)$ in all three cancer cell lines (Fig. 2d and Fig. S3D). Over a wide range of olaparib concentrations, CI numbers were far below 0.5 , and notably, the $\mathrm{CI}$ at the $50 \%$ fraction affected $(\mathrm{Fa})$ level was 0.19 , 0.30 , and 0.35 in the PC-3, SW480, and A549 cell line respectively, indicating strong synergy between ATL and olaparib. As ROS increase could also be induced by lower concentrations of ATL in cancer cells, CI values between a series of lower concentrations of ATL and 5 or $10 \mu \mathrm{M}$ olaparib were determined in PC-3 and SW480 cancer cells, which were all well below 0.5 , indicating that strong synthetic lethality could be achieved at lower ATL concentrations (Fig. 2e).

It is well established that HR deficiency sensitizes cells to PARP inhibition, and factors other than BRCA1/2 mutations can induce HR defects $[44,45]$. To check if the ATL-induced PARPi sensitization was resulted from HR deficiency, we examined the HR status by checking RAD51 foci formation [46] and by monitoring the repair of DSBs using the DR-GFP reporter [47]. We found that RAD51 readily formed ionizing radiation-induced foci in PC-3, SW480 and A549 cells (Fig. 2f and Fig. S4A). Likewise, RAD51 foci were effectively induced by $0.1 \mu \mathrm{M}$ cisplatin in A549 cells (Fig. S4B). The number of RAD51 positive cells were not changed or were increased by ATL or the combination of ATL and olaparib over a $24 \mathrm{~h}$ time period (Fig. $2 \mathrm{f}$ and Fig. S4A, B), indicating that the PC-3, A549, and SW480 cancer cells were able to efficiently assemble recombination filaments, and $10 \mu \mathrm{M}$ ATL alone or in combination with $10 \mu \mathrm{M}$ olaparib did not reduce the recombination capacity. To directly assay HR proficiency, we established stable PC-3 and A549 cell lines harboring the DR-GFP reporter and co-transfected these cells with vectors expressing I-SceI and RFP. Twenty-four hours after transfection, cells were treated with drugs or vehicle control for $12 \mathrm{~h}$. The results showed that nearly all red cells (indicating expression of I-SceI and RFP) overlapped with green cells (indicating recovery of functional GFP gene through HRR) (Fig. S4C), and flow cytometry analyses showed that the numbers of green and red cells were near identical (Fig. S4C) both before and after treatment by the combination of ATL and olaparib, suggesting normal HRR efficiency. Thus, HR-proficient cancer cells were sensitized to olaparib by a nontoxic dose of ATL. Finally, the cytotoxicity of olaparib against the BRCA1-deficient MDA-MB-436 breast cancer cells [48] was further significantly enhanced by 2 and $4 \mu \mathrm{M}$ ATL (Fig. S4D), suggesting that ATL sensitized cancer cells to olaparib through mechanisms other than inducing HR deficiency.

\section{Synergy results from the repair of oxidative DNA damage and PARP-trapping}

The strong synergism between ATL and olaparib inspired us to explore the genetic basis behind it. At first, it was found that the synergistic cytotoxicity was suppressed by NAC (Fig. 2a, b and Fig. S3B), suggesting that it was dependent on the presence of oxidative DNA damage. Supporting this view, both hydrogen peroxide $\left(\mathrm{H}_{2} \mathrm{O}_{2}\right)$ and another TrxR inhibitor auranofin [49], significantly potentiated the cytotoxicity of olaparib in PC-3 cells (Fig. 3a), and the CI values between $0.5 \mu \mathrm{M}$ auranofin and a series of olaparib concentrations in PC-3 and A549 cancer cells also indicated strong synergistic interactions between auranofin and olaparib (Fig. 3b).

The major product of oxidative DNA damage is 8-oxoG which is repaired by the 8-oxoguanine glycosylase (OGG1)-initiated BER [42]. OGG1 exercises oxidized guanine bases and further cleaves the DNA backbone, generating SSBs. PARP1/2 bind the SSBs and recruit XRCC1 to assemble the repair machinery [3]. Thus, inhibition of PARP1/2 or XRCC1 would interfere with the completion of the repair process after 8-oxoG excision, leading to accumulation of SSBs and the potential of forming synergistic cytotoxicity with DNA damaging agents; on the other hand, inhibition of OGG1 would suppress the formation of SSB and mitigate the impact of PARP or XRCC1 inhibition. Indeed, shRNA-mediated knockdown of OGG1, or co-incubation with the OGG1 inhibitor O8, significantly improved cell viability of the combination treatment group (Fig. 3c, d and Fig. S5A, B), indicating that a significant portion of the synergistic cytotoxicity resulted from DNA base excision repair of ATL-induced 8-oxoG.

Unexpectedly, knockdown of PARP1 did not synergize with $10 \mu \mathrm{M}$ ATL to yield synergistic cytotoxicity (Fig. 3c, e and Fig. S5A, C); on the contrary, PARP1 depletion greatly reduced the cytotoxicity of the ATL and olaparib combination (Fig. 3d and Fig. S5B). These results indicated that inhibition of PARP enzymatic activity was not important but the presence of the PARP1 protein was required for the 

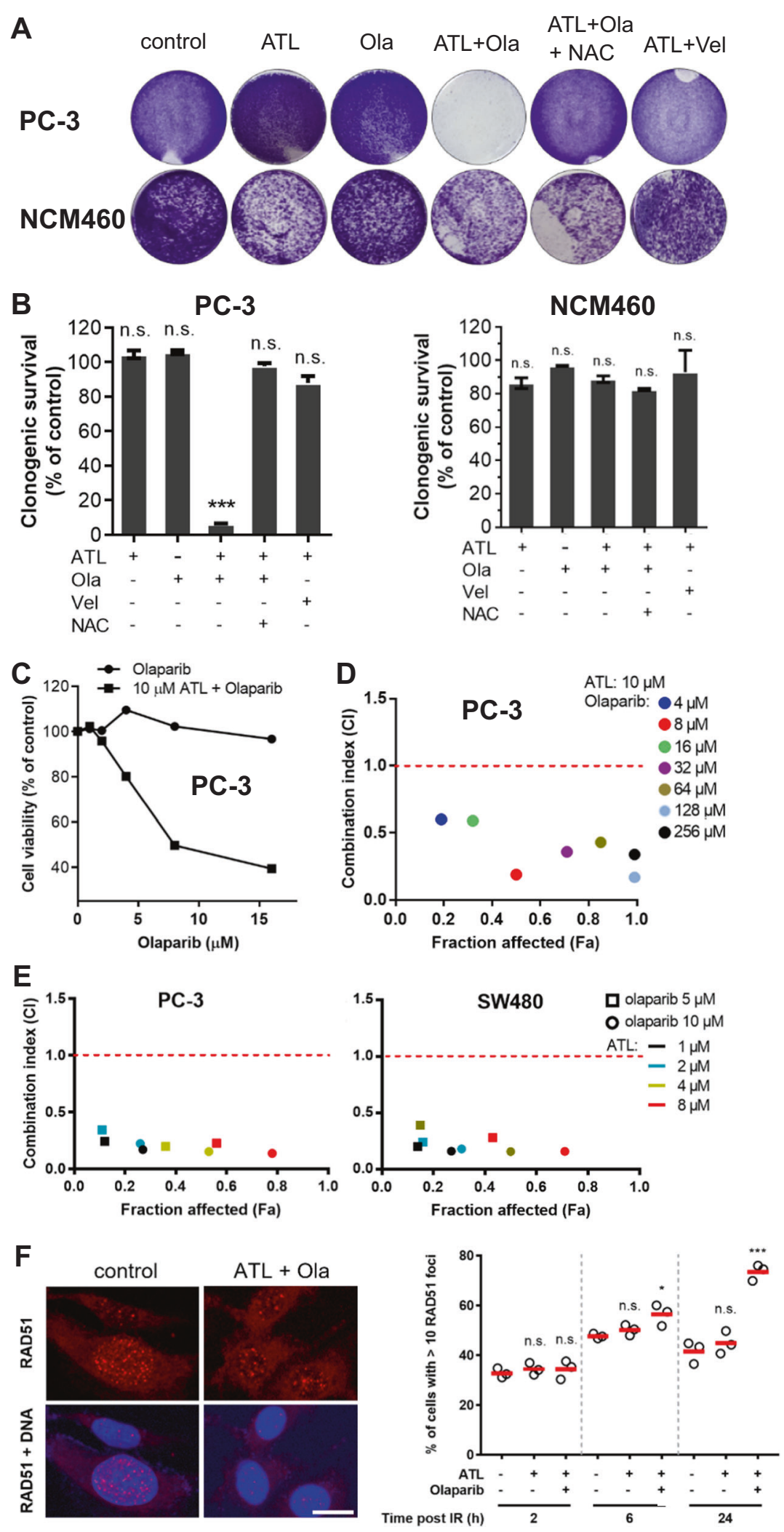

cytotoxicity of the ATL and olaparib combination, thus supporting PARP-trapping as the principle mechanism underlying the synergy between ATL and olaparib.
Olaparib and veliparib are two different PARP inhibitors with equivalent enzymatic inhibition potency. However, olaparib is substantially more potent than veliparib at 
Fig. 2 Olaparib and ATL synergize to result in synthetic lethality in HR-proficient cancer cells. a Colony formation assay. PC-3 and NCM460 cells were treated by $10 \mu \mathrm{M}$ ATL, $10 \mu \mathrm{M}$ olaparib (Ola), or combination of $10 \mu \mathrm{M}$ ATL and $10 \mu \mathrm{M}$ Ola or $10 \mu \mathrm{M}$ ATL and $10 \mu \mathrm{M}$ veliparib (Vel) for 7 days. The combination of $10 \mu \mathrm{M}$ ATL and $10 \mu \mathrm{M}$ Ola, but not $10 \mu \mathrm{M}$ ATL and $10 \mu \mathrm{M}$ Vel, completely inhibited the clonogenic growth of PC-3 but not the NCM460 cells and $10 \mathrm{mM}$ NAC blocked the inhibition. b Quantification of colony formation assay. Cells stained by crystal violet were dissolved in $70 \%$ ethanol and absorbance at $595 \mathrm{~nm}$ was measured using a microplate reader. Data were presented as mean \pm SD of three independent experiments. c MTT proliferation assay. PC-3 cells were treated by $1,2,4,8$, or $16 \mu \mathrm{M}$ olaparib alone or combined with $10 \mu \mathrm{M}$ ATL for $72 \mathrm{~h}$. Olaparib in combination with $10 \mu \mathrm{M}$ ATL dose-dependently inhibited the growth of PC-3 cells, while olaparib alone had no impact. d Determination of combination index (CI) values. PC-3 cells were treated by $10 \mu \mathrm{M}$ ATL and the indicated concentrations of olaparib for $72 \mathrm{~h}$. The CI values were determined by the Chou-Talalay method using the CompuSyn software. e CI values between lower concentrations of ATL and olaparib. PC-3 or SW480 cells were treated by 5 or $10 \mu \mathrm{M}$ olaparib and the indicated concentrations of ATL for $72 \mathrm{~h}$. f RAD51 foci formation after ionizing radiation (IR) exposure. PC-3 cells were irradiated with $3 \mathrm{~Gy}$ X-rays, treated with vehicle control, $10 \mu \mathrm{M}$ ATL alone or in combination with $10 \mu \mathrm{M}$ olaparib (Ola), and immunostained at the indicated time points. Left: representative micrographs of PC-3 cells stained with anti-RAD51 and counterstained with DAPI $2 \mathrm{~h}$ post IR (scale bar: $10 \mu \mathrm{m}$ ). Right: quantification of the percentage of cells with more than 10 RAD51 foci at the indicated time points post IR. n.s. not significant, $* p<0.05$, $* * * p<0.001$ vs. vehicle control.

trapping PARP on damaged DNA $[14,15]$. Consistently, in the presence of ATL, olaparib but not veliparib, greatly increased accumulation of PARP1 protein in the chromatinbound fraction (Fig. 3f and Fig. S5D). And similar to PARP1 knockdown, veliparib did not synergize with ATL to inhibit the clonogenic survival of the PC-3, SW480 and A549 cancer cells (Fig. 2a, b and Fig. S3B), despite that both veliparib and olaparib efficiently suppressed PAR accumulation (Fig. $3 f$ and Fig. S5D). Taking together, these results showed that the synergy between ATL and olaparib resulted primarily from the formation of trapped PARPDNA complexes during the repair of ATL-induced oxidative DNA damage.

\section{Trapped PARP-DNA complexes induce intense replication stress and DSB}

Next, we assessed the molecular consequences caused by the synergistic interactions between olaparib and ATL. Treatment by the combination of ATL and olaparib for $12 \mathrm{~h}$, but not by each agent alone, resulted in a marked increase in the number of cancer cells with high-intensity, pan-nuclear $\gamma \mathrm{H} 2 \mathrm{AX}$ staining as well as the total number of $\gamma \mathrm{H} 2 \mathrm{AX}$ positive cancer cells (Fig. 4a, b and Fig. S6A), indicating induction of intense replication stress [50] and/ or DSBs [51] specifically by the combination of ATL and olaparib. The staining intensity of $\gamma \mathrm{H} 2 \mathrm{AX}$ was significantly reduced by NAC (Fig. 4a, b and Fig. S6A), correlating it with oxidative DNA damage. Pulse-labeling of DNA replicating cells by EdU showed that most $\gamma \mathrm{H} 2 \mathrm{AX}$ positive cells were co-labeled by EdU (Fig. $4 \mathrm{a}-\mathrm{c}$ and Fig. S6A), and the DNA replication inhibitor aphidicolin significantly reduced $\gamma \mathrm{H} 2 \mathrm{AX}$ staining (Fig. $4 \mathrm{a}$, b and Fig. S6A) and $\gamma \mathrm{H} 2 \mathrm{AX}$ protein levels (Fig. 4d), suggesting that induction of $\gamma \mathrm{H} 2 \mathrm{AX}$ was highly specific to $\mathrm{S}$-phase cells likely as a result of collision between DNA replication forks and the trapped PARP-DNA complexes. The combination of veliparib and ATL induced a much smaller increase in $\gamma \mathrm{H} 2 \mathrm{AX}$ levels (Fig. 4d), implicating inhibition of PARP enzymatic activity as a weak inducer of $\gamma \mathrm{H} 2 \mathrm{AX}$ in ATL-treated cells.

Consistent with the strong and time-dependent induction of $\gamma \mathrm{H} 2 \mathrm{AX}$ (Fig. 4e and Fig. S6B), protein levels of phosphorylated Chk1 and Chk2 were significantly increased by the combination of ATL and olaparib (Fig. 4e and Fig. S6B), demonstrating strong activation of both ATR-Chk1 and ATM-Chk2 DNA damage response pathways [52]. Furthermore, the amounts of chromatin-bound replication protein A (RPA) were markedly increased (Fig. $4 \mathrm{f}-\mathrm{h}$ and Fig. S6C) in the combination treatment group, indicating mass production of single-stranded DNA (ssDNA), a sign of replication fork stalling and intense replication stress [53]. In addition, we labeled the PC-3 cells by CIdU for 30 min right before a 3 -h drug treatment, and then by IdU for $30 \mathrm{~min}$ immediately after drug treatment (Fig. 5a). Almost the same population of cells were labeled by CIdU and IdU in the control and mono-agent treatment groups, however, compared to CIdU labeled cells, there was a sharp drop in the number of IdU positive cells as well as IdU staining intensity in the drug combination group (Fig. 5b, c), reflecting severe replication fork stalling.

Running the comet assay under a neutral condition, we found that a significant amount of DSBs were accumulated in the cancer cells treated by the combination of ATL and olaparib for $12 \mathrm{~h}$ (Fig. 5d and Fig. S7A). Bigger and longer comet tails were revealed by the alkaline comet assay (Fig. $5 \mathrm{~d}$ and Fig. S7A), indicating the presence of a large number of SSBs. Moreover, 53BP1 foci, which represent sites of double strand DNA breaks [54], were markedly increased in the cancer cells treated by the combination of ATL and olaparib for $12 \mathrm{~h}$ and both NAC and the DNA replication inhibitor aphidicolin dramatically reduced the number of 53BP1 positive cells (Fig. 5e and Fig. S7B).

\section{Activation of DNA damage response leads to apoptosis after $G_{2}$ arrest}

Given the intense replication stress and strong activation of both Chk1 and Chk2, we assessed cell cycle distribution in response to treatment by the combination of ATL and olaparib. Flow cytometry analyses showed that there was a 
Fig. 3 Synergy between olaparib and ATL results from PARP-trapping. a Both hydrogen peroxide and auranofin sensitize cancer cells to olaparib. PC-3 cells were treated by $1,2,4,8$, or $16 \mu \mathrm{M}$ olaparib alone or combined with $100 \mu \mathrm{M} \mathrm{H}_{2} \mathrm{O}_{2}$ or $0.5 \mu \mathrm{M}$ auranofin for $72 \mathrm{~h}$. Olaparib in combination with $100 \mu \mathrm{M} \mathrm{H}_{2} \mathrm{O}_{2}$ or $0.5 \mu \mathrm{M}$ auranofin dosedependently inhibited the growth of PC-3 cells, while olaparib alone had no impact. NAC blocked $\mathrm{H}_{2} \mathrm{O}_{2}$ or auranofin-induced olaparib sensitization. b CI values between auranofin and olaparib indicate strong synergy. PC-3 or A549 cells were treated by $0.5 \mu \mathrm{M}$ auranofin and the indicated concentrations of olaparib for $72 \mathrm{~h}$. c Western blot verification of shRNA-mediated knockdown of OGG1 and PARP1 in PC-3 cells. d MTT proliferation assay. Wild-type, OGG1-depleted or inhibited by $8 \mu \mathrm{M}$ O8, and PARP1-depleted PC-3 cells were treated by 2,4 , 8 , or $16 \mu \mathrm{M}$ olaparib in combination with $10 \mu \mathrm{M}$ ATL for $72 \mathrm{~h}$. e MTT assay. Wildtype or PARP1 depleted PC-3 cells were treated by $10 \mu \mathrm{M}$ ATL or the combination of $10 \mu \mathrm{M}$ ATL and $10 \mu \mathrm{M}$ olaparib (Ola) for $72 \mathrm{~h}$. PARP1

knockdown did not sensitize PC-3 cells to $10 \mu \mathrm{M}$ ATL.

f Detection of chromatin-bound PARP1 by Western blot. PC-3 cells were treated by $10 \mu \mathrm{M}$ ATL, $10 \mu \mathrm{M}$ olaparib (Ola), $10 \mu \mathrm{M}$ veliparib (Vel), or the combination of $10 \mu \mathrm{M}$ ATL with $10 \mu \mathrm{M}$ olaparib or veliparib for 24 h. n.s. not significant, $* * * p<$ 0.001 vs. vehicle control.
A

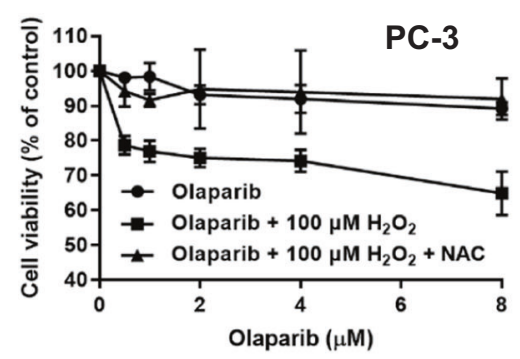

B

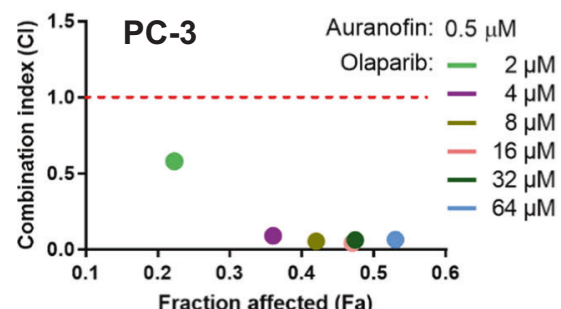

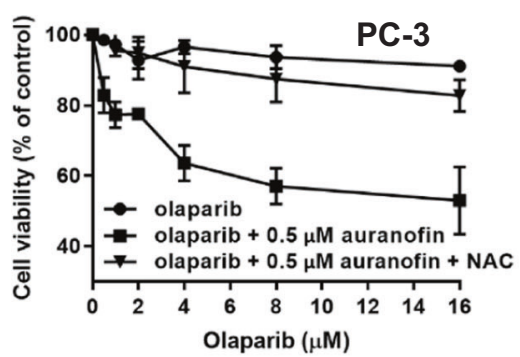

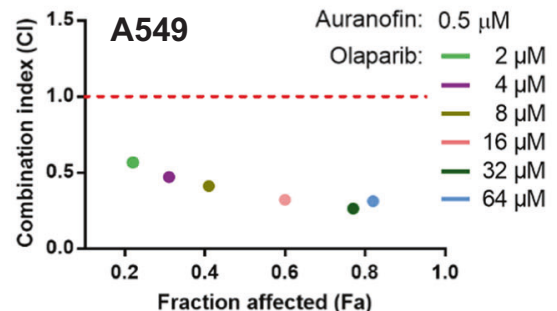

C

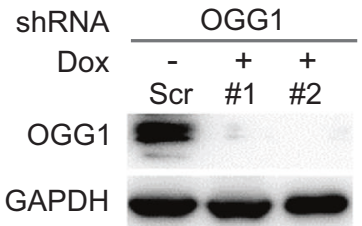

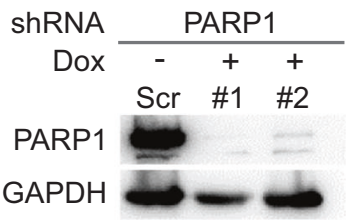

D

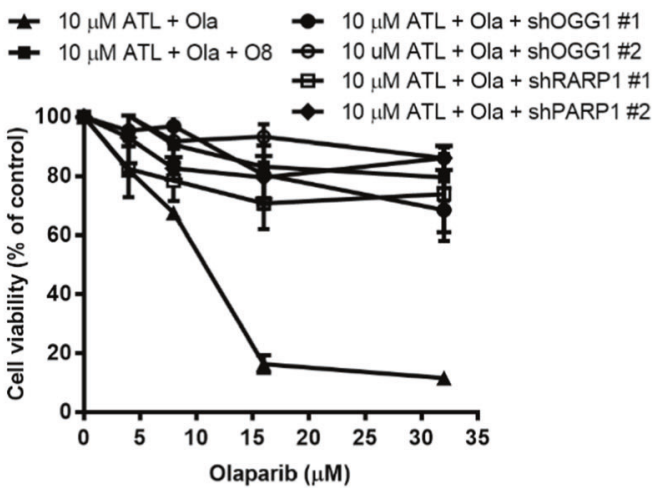

E

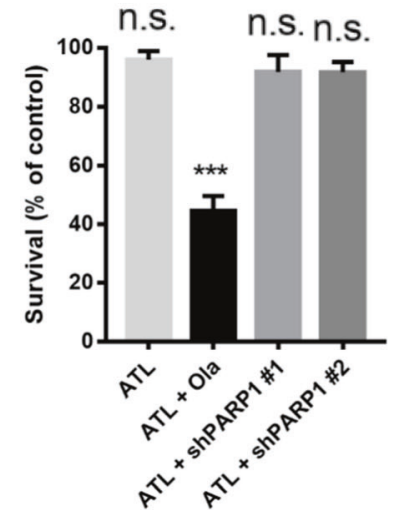

$\mathbf{F}$
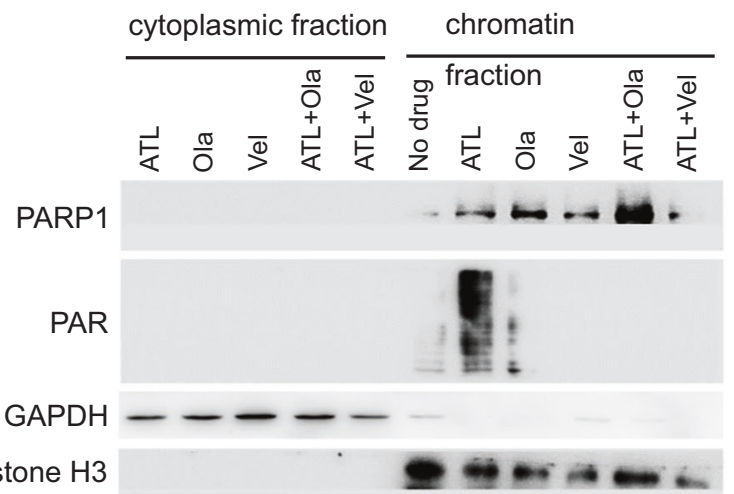

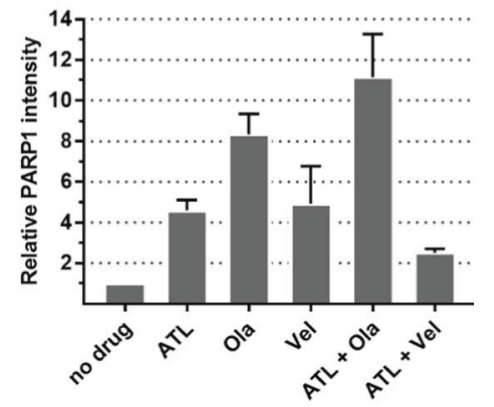

fast, progressive accumulation of cells in the $S$ and $G_{2} / M$ phases within the first $48 \mathrm{~h}$ of treatment (Fig. $6 \mathrm{a}, \mathrm{b}$ and Fig. S8A). As the levels of phosphorylated histone $\mathrm{H} 3$ decreased sharply (Fig. 6c and Fig. S8B), suggesting the cells in the $\mathrm{G}_{2} / \mathrm{M}$ population were mainly in early-to-mid $\mathrm{G}_{2}$ phase
[55], these results indicated activation of both the $\mathrm{S}$ and the $\mathrm{G}_{2} / \mathrm{M}$ cell cycle checkpoints. Interestingly, as the treatment continued beyond $48 \mathrm{~h}$, the $\mathrm{G}_{2}$ but not the $S$ population, started to shrink, showing a significant reduction by the end of $72 \mathrm{~h}$ of treatment (Fig. 6a, b and Fig. S8A); 
Fig. 4 ATL synergizes with olaparib to induce intense replication stress in cancer cells. a Immunofluorescent staining of $\gamma \mathrm{H} 2 \mathrm{AX}$ and EdU. PC-3 cells were treated by $10 \mu \mathrm{M}$ ATL, $10 \mu \mathrm{M}$ olaparib (Ola) or the combination of the two, with or without $10 \mathrm{mM}$ NAC or $5 \mu \mathrm{M}$ aphidicolin (APC), for $12 \mathrm{~h}$. At the end of drug treatment, cells were pulselabeled with $10 \mu \mathrm{M}$ EdU for 20 min (scale bar: $20 \mu \mathrm{m}$ ). b, c $\gamma \mathrm{H} 2 \mathrm{AX}$ and EdU positive cells were measured using the ImageJ software and the data were processed by the Prism software. d Western blot detection of $\gamma \mathrm{H} 2 \mathrm{AX}$. PC-3 cells were treated by the combination of $10 \mu \mathrm{M}$ ATL and $10 \mu \mathrm{M}$ Ola or $10 \mu \mathrm{M}$ ATL and $10 \mu \mathrm{M}$ veliparib (Vel), with or without $5 \mu \mathrm{M}$ aphidicolin (APC), for $24 \mathrm{~h}$. e Western blot analysis of the indicated proteins. PC-3 cells were treated by $10 \mu \mathrm{M}$ ATL, $10 \mu \mathrm{M}$ olaparib (Ola) or the combination of the two for the indicated times.

f Immunofluorescent staining of RPA32 foci. PC-3 cells were treated by $10 \mu \mathrm{M}$ ATL, $10 \mu \mathrm{M}$ olaparib (Ola) or the combination of the two for $12 \mathrm{~h}$ (scale bar: $10 \mu \mathrm{m}$ ). g Nuclear RPA32 intensity was measured using the ImageJ software and the data were processed by the Prism software. h Western blot detection of chromatin bound RPA32 and $\gamma \mathrm{H} 2 \mathrm{AX}$. PC-3 cells were treated by $10 \mu \mathrm{M}$ ATL, $10 \mu \mathrm{M}$ olaparib (Ola) or the combination of the two for the indicated times. n.s. not significant, $* * p<0.01, * * * * p<$ 0.0001 vs. vehicle control.
A

DAPI

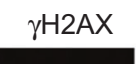

定
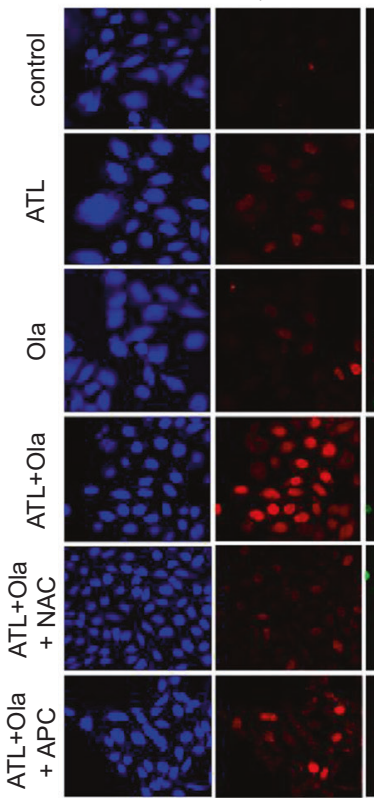

E
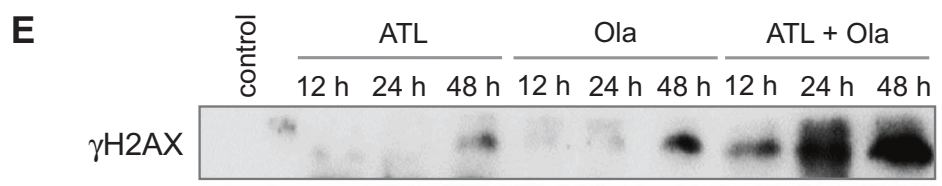

Chk1-pS317

Chk1

Chk2-pT68

Chk2

GAPDH

F

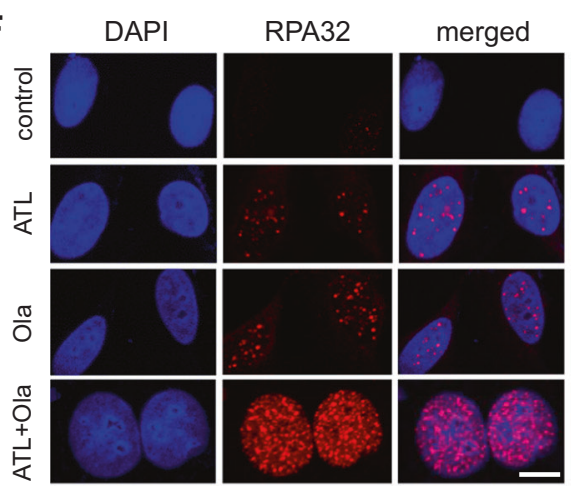

EdU
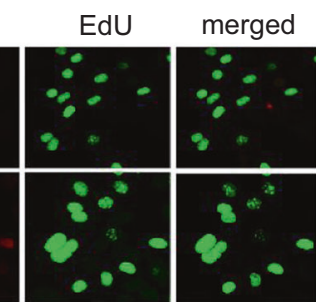
$\%$
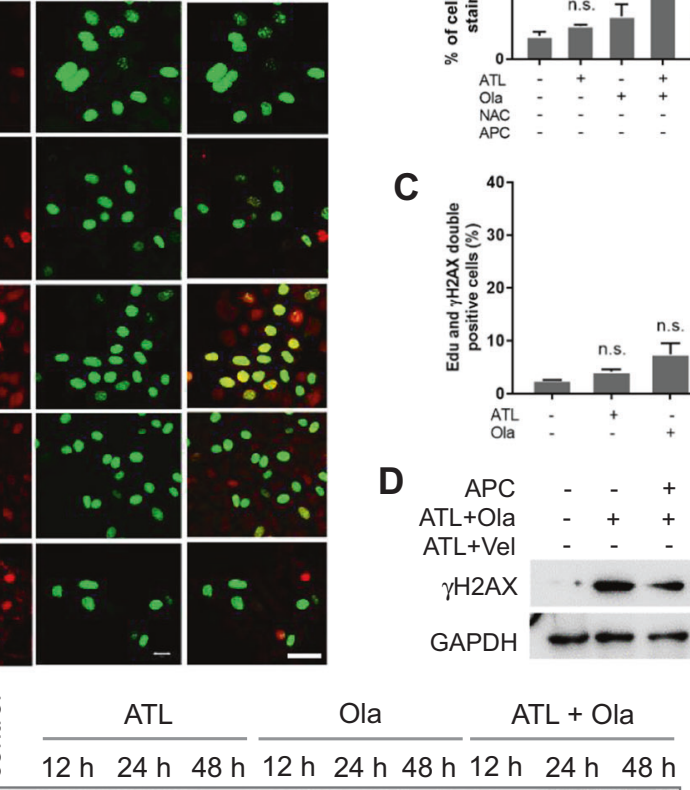

B

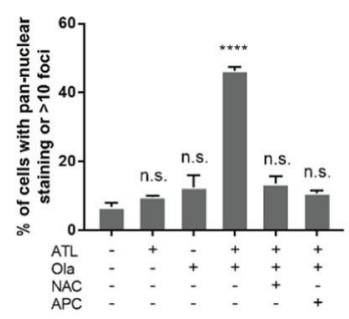

C

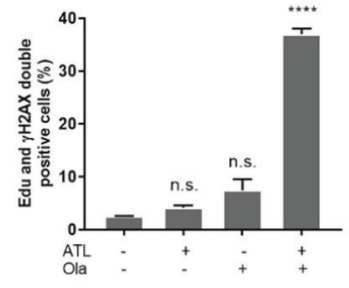

D
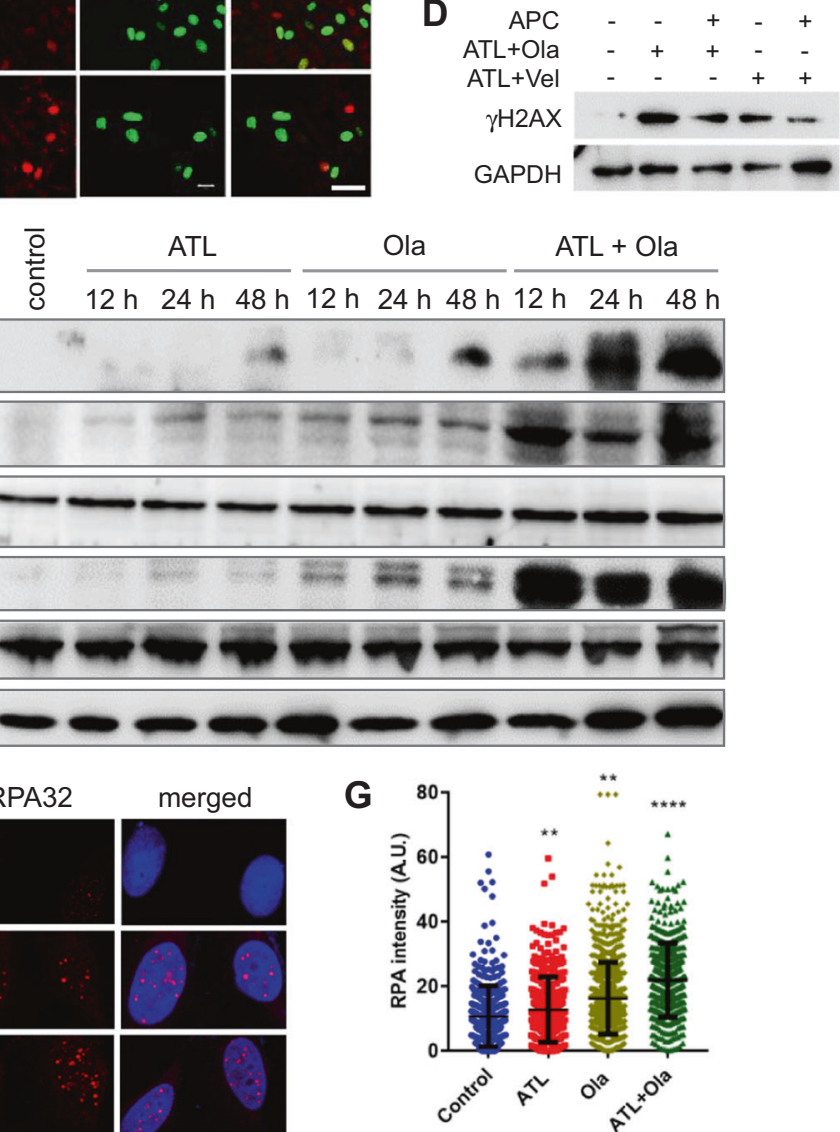

H

Chromatin fraction

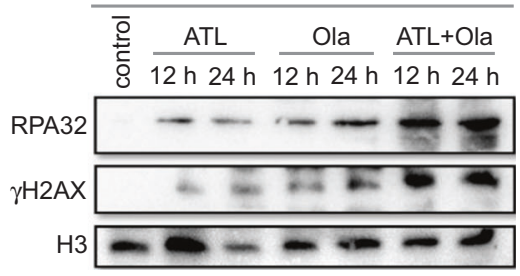

meanwhile, the sub- $\mathrm{G}_{1}$ population increased dramatically (Fig. 6a and Fig. S8A), suggesting increased cell death after $\mathrm{G}_{2}$ arrest.
To check if the cell death was caused by apoptosis, we tracked the dynamic changes of cleaved caspase 3 by Western blot and Annexin V-positive cells by flow 
Fig. 5 ATL synergizes with olaparib to induce replication fork stalling and DSB in cancer cells. a Schedule of CIdU and IdU labeling and drug treatment. b Representative images of CIdU and IdU positive PC-3 cells (scale bar: $25 \mu \mathrm{m})$. $\mathbf{c}$ The percentage of CIdU and IdU positive cells in three wells. d Representative images of neutral and alkaline comet assay. PC-3 cells were treated by vehicle control or the combination of $10 \mu \mathrm{M}$ ATL and $10 \mu \mathrm{M}$ olaparib (Ola) for $12 \mathrm{~h}$. e Immunofluorescent staining of 53BP1. PC-3 cells were treated by $10 \mu \mathrm{M}$ ATL, $10 \mu \mathrm{M}$ olaparib (Ola) or the combination of the two, with or without $10 \mathrm{mM}$ NAC or $5 \mu \mathrm{M}$ aphidicolin (APC), for $12 \mathrm{~h}$. 53BP1 positive cells were measured using the Image J software and the data were processed by the Prism software. $* * * p<0.001, * * * * p<$ 0.0001 vs. vehicle control.
A
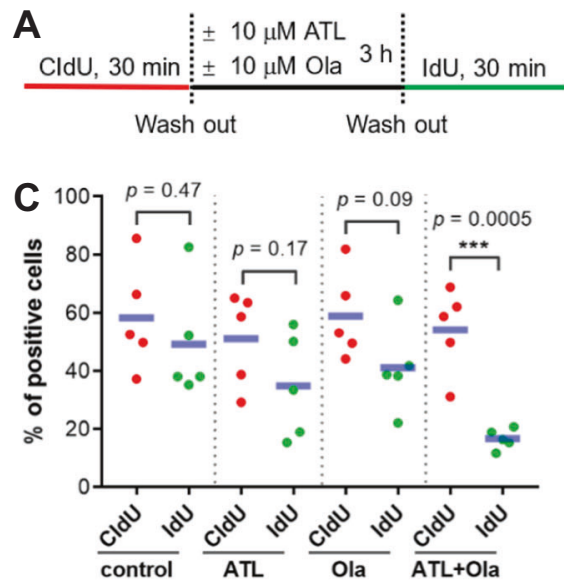

D
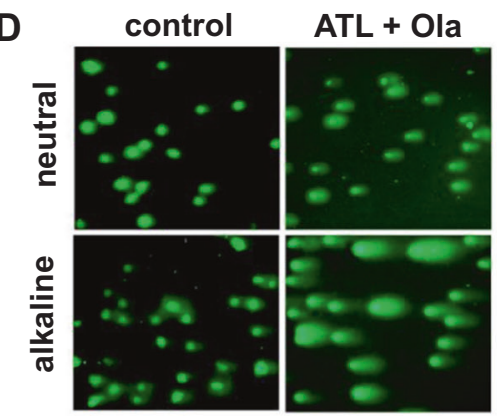

E

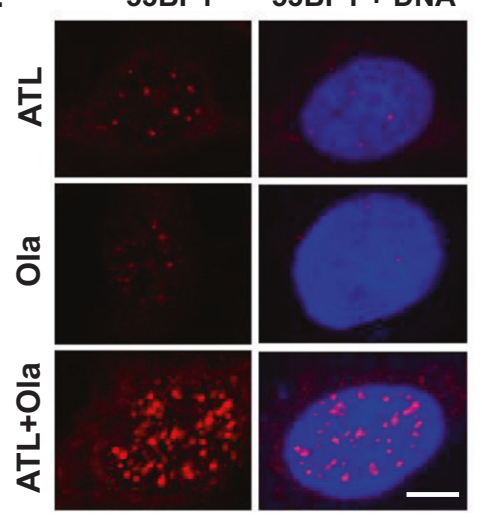

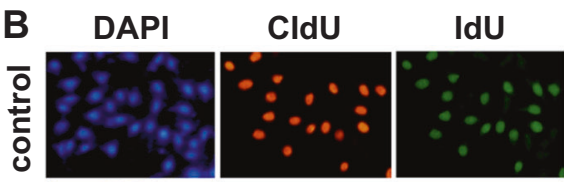
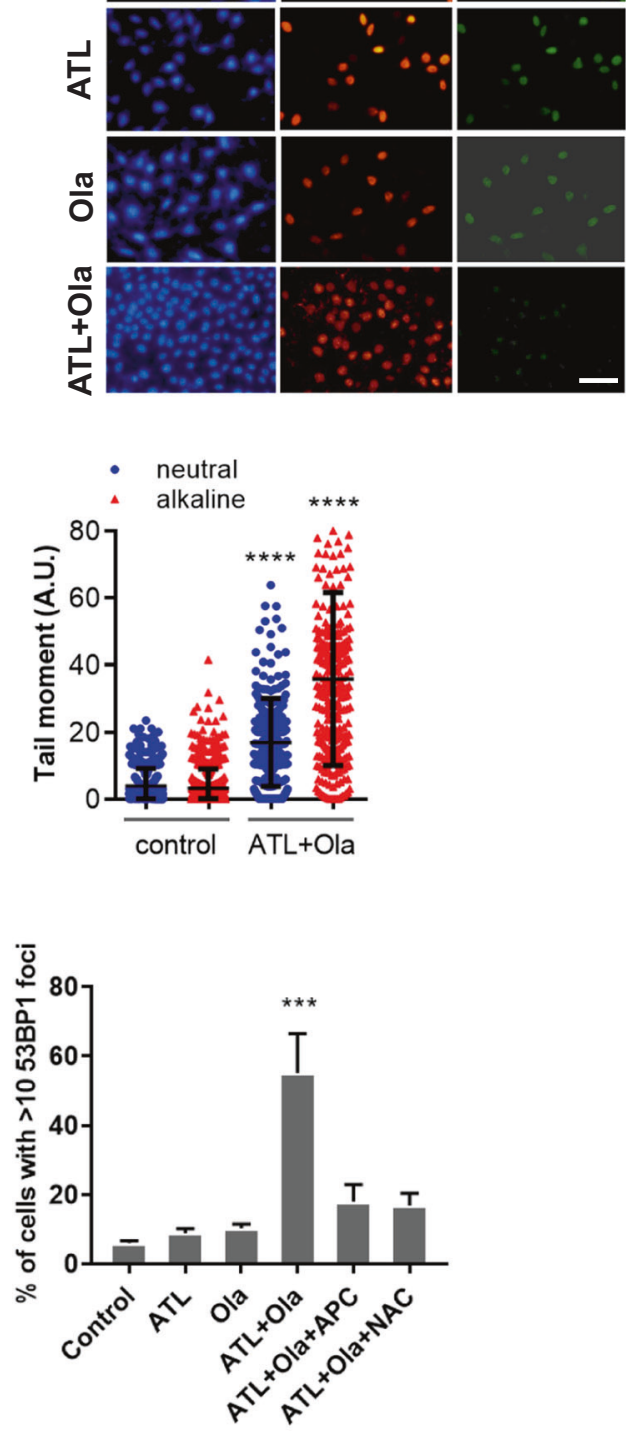

cytometry in response to treatment by the combination of ATL and olaparib. The results showed a rapidly progressive increase in the levels of cleaved caspase 3 (Fig. $6 \mathrm{~d}$ and Fig. $\mathrm{S} 8 \mathrm{C}$ ) and in the size of the Annexin V-positive cell population (Fig. 6e and Fig. S8D). By the end of $72 \mathrm{~h}$ of treatment, $67 \%$ of the PC-3 cancer cells were positive for Annexin V-FITC, however, most of them were propidium iodide (PI) negative, indicating they were in early apoptosis, a sign of rapid induction and turnover of apoptotic cells. Treatment by the pan-caspase inhibitor Z-VAD-FMK suppressed the increase in Annexin V-positive cells (Fig. 6e and Fig. S8D), confirming the presence of caspasedependent apoptosis. Together, these results showed that the synergistic cytotoxicity of ATL and olaparib resulted from $\mathrm{S}$ and $\mathrm{G}_{2}$ cell cycle arrest and subsequent induction of apoptosis.

\section{Coadministration of ATL and olaparib suppresses tumor growth in vivo}

To assess the therapeutic effect of the ATL and olaparib combination in vivo, mice bearing PC-3 tumor xenografts were treated with either ATL (dosed once daily by oral gavage, $50 \mathrm{mg} / \mathrm{kg}$ ), olaparib (dosed once daily by intraperitoneal injection, $50 \mathrm{mg} / \mathrm{kg}$ ), or the combination of the 2 for 15 days. Treatment with either agent alone had no impact on tumor growth as compared to the vehicle control, however, the combination of ATL and olaparib completely 
A

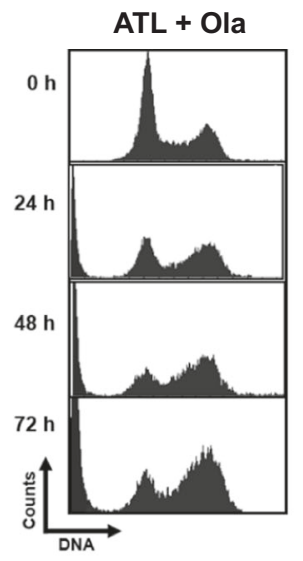

B

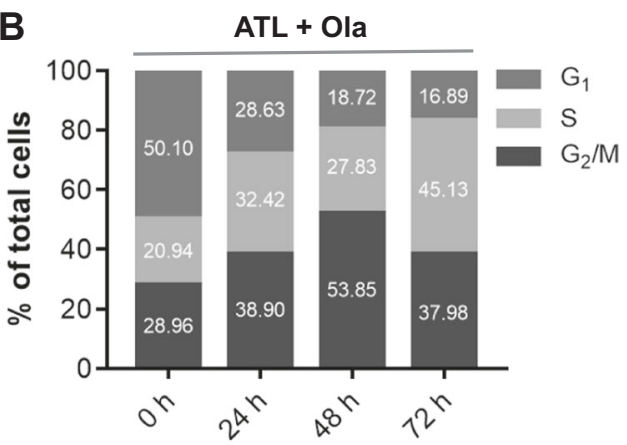

\section{C}
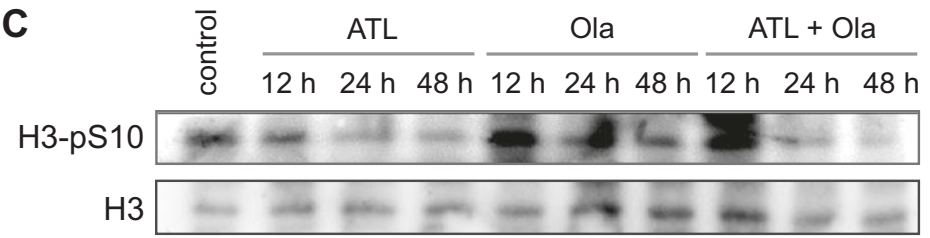

D

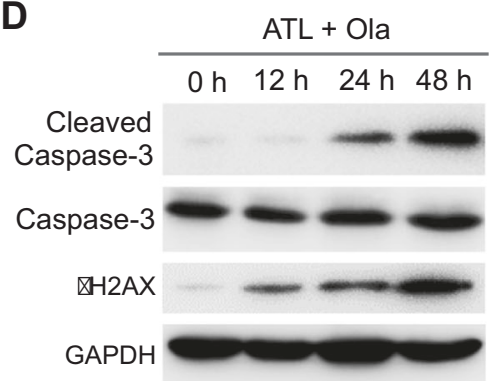

Fig. 6 Induction of cell cycle arrest and apoptosis by ATL and olaparib. a, b Flow cytometry analysis of cell cycle distribution. Treatment by the combination of $10 \mu \mathrm{M}$ ATL and $10 \mu \mathrm{M}$ olaparib (Ola) caused progressive accumulation of PC-3 cells in the S and $\mathrm{G}_{2} / \mathrm{M}$ phases within the first $48 \mathrm{~h}$, and then the $\mathrm{G}_{2} / \mathrm{M}$ but not the $S$ population started to fall, meanwhile, the sub- $\mathrm{G}_{1}$ population increased steadily. c Western blot analysis of phosphorylated H3. The levels of H3-pS10 in PC-3 cells decreased sharply after treatment by the combination of $10 \mu \mathrm{M}$ ATL and $10 \mu \mathrm{M}$ olaparib (Ola) for $12 \mathrm{~h}$ and longer, indicating that the cells in the $G_{2} / M$ population were in early-to-mid $G_{2}$ phase.

inhibited the growth and caused substantial regression of the tumor (Fig. 7a-c). Immunohistochemical staining of the tumor tissues showed significantly increased $\gamma \mathrm{H} 2 \mathrm{AX}$ signals, which were accompanied by intense apoptosis revealed by TUNEL staining, only in the group treated by the combination of ATL and olaparib (Fig. 7d), suggesting that tumor regression likely resulted from DNA damageinduced apoptosis. No significant body weight loss was observed in the treated groups compared with the control group (data not shown), and microscopic examination of hematoxylin-eosin stained tissue sections of vital organs (liver, heart, and kidney) did not show any histological change that would indicate toxic effects of ATL (Fig. 7e),

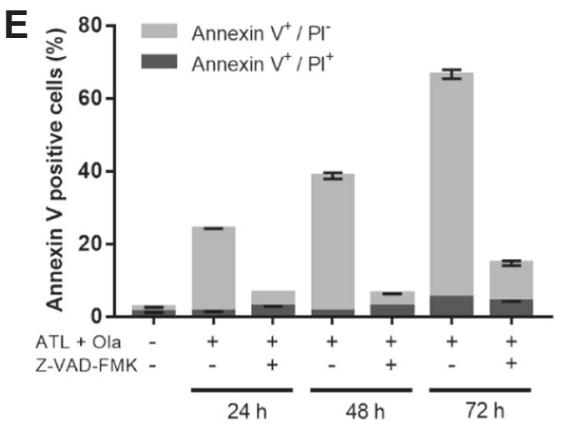

d Western blot analysis of cleaved caspase 3. Treatment by the combination of $10 \mu \mathrm{M}$ ATL and $10 \mu \mathrm{M}$ olaparib (Ola) caused a rapidly progressive increase in the levels of cleaved caspase 3 in the PC- 3 cell line. e Flow cytometry analysis of apoptosis in PC-3 cells. Treatment by the combination of $10 \mu \mathrm{M}$ ATL and $10 \mu \mathrm{M}$ olaparib (Ola) caused a time-dependent increase in Annexin V-positive cells, most of which were propidium iodide (PI) negative, indicating they were in early apoptosis. The pan-caspase inhibitor Z-VAD-FMK suppressed the increase in Annexin V-positive cells.

suggesting the combination of ATL and olaparib was well tolerated.

\section{Discussion}

DNA damage and defective DNA repair promote mutations and tumorigenesis but also render cancer cells vulnerable to additional DNA damage or disruption of compensatory DNA repair pathways $[1,2,56]$. Exploiting such vulnerabilities to target cancer is emerging as a promising and highly selective anticancer strategy. Cancer cells with deficient HR are exquisitely sensitive to inhibition of PARP 
Fig. 7 Coadministration of ATL and olaparib induces regression of tumor xenografts. PC-3 cells $\left(2 \times 10^{6}\right)$ in $1: 1$ matrigel were inoculated subcutaneously into the left flanks of male athymic BALB/c nude mice. When the tumor volume reached approximately $150 \mathrm{~mm}^{3}$ (15 days after inoculation), mice were treated once daily with $50 \mathrm{mg} / \mathrm{kg}$ ATL oral gavage or $50 \mathrm{mg} / \mathrm{kg}$ olaparib intraperitoneal injection or both for 15 days.

a Photograph of tumors dissected out from each mouse at the time of study termination. b Tumor volumes measured on the indicated days of treatment. Results were shown as mean \pm SD. c Tumor weight measured at the end of the study.

d Representative images of immunohistochemical staining of $\gamma \mathrm{H} 2 \mathrm{AX}$ and TUNEL in tumor tissues (scale bar: $20 \mu \mathrm{m}$ ).

e Hematoxylin-eosin staining of liver, heart, and kidney tissue sections (magnification: $\times 400$ ). $n . s$. not significant, $* * * p<0.001$ vs. vehicle control.
A
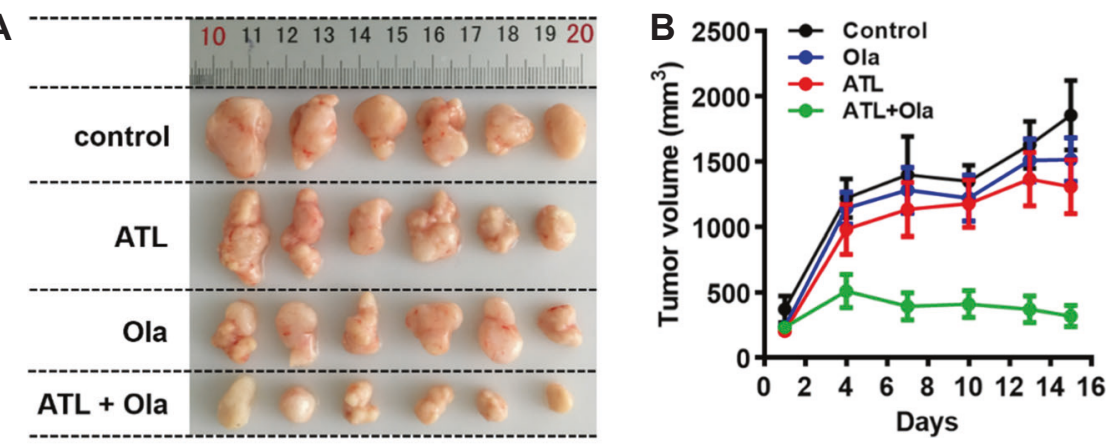

C

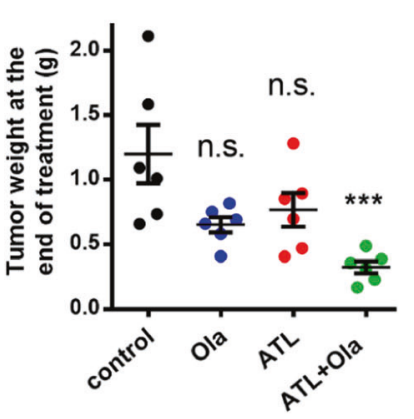

D $\gamma \mathrm{H} 2 \mathrm{AX}$
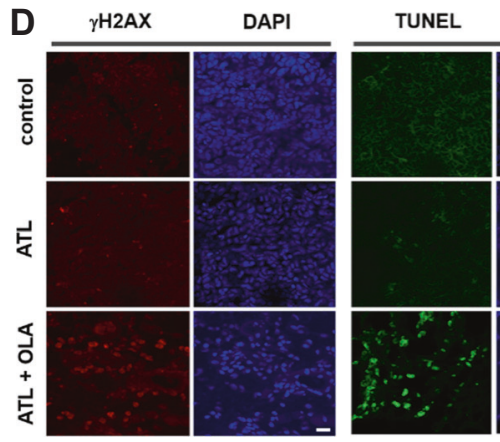

E

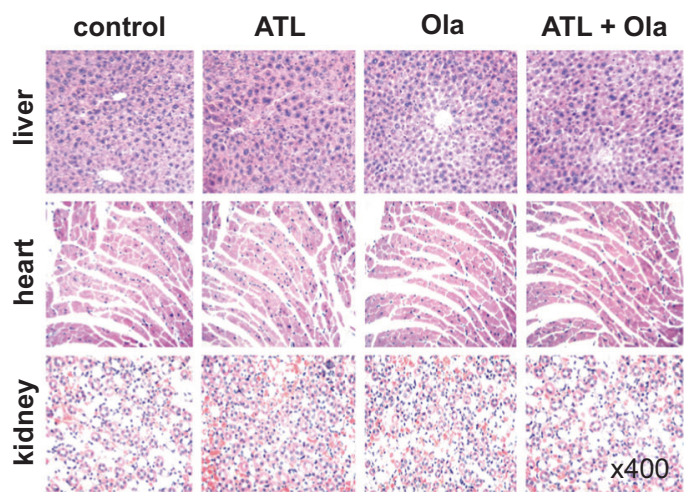

$[12,13]$ and several PARPis are now approved for the treatment of BRCA1/2-mutated ovarian and breast cancers, with dozens more in various stages of preclinical and clinical development $[15,16]$. However, most ovarian and breast cancers, and nearly all other types of cancer, have normal BRCA1 and BRCA2; and even in BRCA1/2-mutant tumors, responses to PARPi are heterogeneous and initially responsive cancers eventually develop PARPi resistance. Thus, developing strategies to broaden the therapeutic potential of PARPis and to overcome PARPi resistance is of great importance.

Studies in the past have shown that inhibition of PARP can sensitize cancer cells to DNA damaging cytotoxic agents irrespective of HR status [17, 18], however, clinical use of PARPis in combination with DNA damaging chemotherapy is limited due to normal tissue toxicity [16]. ROS are a major class of DNA-damaging agents and play very important roles in suppressing cancer initiation and progression [25, 26, 57-60]. Owing to dysregulated proliferation, cancer cells exhibit abnormal metabolism and high levels of intrinsic oxidative pressure, leading to their dependence on antioxidant systems and DNA repair for survival [26, 59-62]. The thioredoxin antioxidant pathway is upregulated in tumors and simultaneous inhibition of the thioredoxin and glutathione antioxidant pathways causes synergistic cancer cell death [26]. These features render cancer cells more sensitive to exogenous oxidative insult than normal cells, thus providing a unique opportunity to induce DNA damage selectively in cancer cells by targeting antioxidant systems or promoting ROS generation [27, 41].

ATL is a natural sesquiterpene lactone that shares a $\alpha$ methylene- $\gamma$-lactone moiety with known TrxR inhibitors [34]. It binds to TrxR and irreversibly inhibits the enzymatic activity of both purified and cellular TrxR, resulting in marked elevation of oxidized thioredoxin and ROS in cancer cells. Overexpression of functional TrxR attenuated 
ATL-induced accumulation of ROS and cancer cell toxicity [34]. Here we showed that a noncytotoxic dose of ATL induced a rapid increase in ROS levels specifically in cancer cells. The ATL-induced, cancer-specific ROS increase was followed by NAC-suppressible accumulation of 8-oxoG, DNA strand breaks and PAR, indicating generation of oxidative DNA damage and activation of PARP1/2. These results demonstrated the potential of using nontoxic doses of ATL to produce oxidative DNA damage selectively in cancer cells. Currently, pharmacokinetics (PK) data of ATL in humans are not available, however, studies in rat reported a plasma $C_{\max }$ of $1.103 \mathrm{mg} / \mathrm{L}(4.75 \mu \mathrm{M})$ after intravenous administration of Radix Inulae extract containing $3.43 \mathrm{mg} /$ $\mathrm{kg} \mathrm{ATL}$ [63] and $0.03 \mathrm{mg} / \mathrm{L}(0.12 \mu \mathrm{M})$ after oral administration at a dose of $50 \mathrm{mg} / \mathrm{kg}$ ATL [64]. Our results showed that a significant increase in ROS levels could be induced in cancer cells by an ATL concentration as low as $0.625 \mu \mathrm{M}$ and strong synthetic lethality was achieved by $1 \mu \mathrm{M}$ ATL combined with olaparib. Thus, it appears that an effective ATL concentration may be achievable in vivo at least through intravenous administration, and ATL could serve as a chemical scaffold to be further developed.

Remarkably, adding a nontoxic dose of the PARPi olaparib to nontoxic ATL resulted in potent synergistic cytotoxicity specifically in cancer cells. The toxicity was directly related to ATL-induced oxidative damage as it was significantly reduced by NAC. OGG1 depletion or inhibition significantly reduced the synergistic cytotoxicity, revealing that the lethality resulted primarily from the repair of oxidized DNA bases. The non-trapping PARPi veliparib did not synergize with ATL to cause cytotoxicity and depletion of PARP1 did not sensitize cells to nontoxic ATL, on the contrary, the synergistic toxicity between ATL and olaparib was abolished in the absence of PARP1, demonstrating that the lethality associated with the ATL and olaparib combination was dependent on PARP-trapping.

Trapped PARP-DNA complexes, together with unrepaired SSBs, collide with ongoing DNA replication forks to result in fork stalling and replication stress $[3,10]$. In the cancer cells treated by the combination of ATL and olaparib, the markedly increased levels of $\gamma \mathrm{H} 2 \mathrm{AX}$ and chromatinbound RPA indicated intense replication stress [50,53], and the CIdU and IdU labeling experiment revealed severe fork stalling. Rapid generation of an excessive number of stalled replication forks, together with impaired fork reversal and restart associated with PARP inhibition, promote fork collapse and generation of lethal DSBs [3, 4]. The results of the comet assay and 53BP1 staining confirmed the presence of extensive DSBs. In addition, generation of ssDNA due to fork stalling may exhaust the RPA pool to result in replication catastrophe [53].

Oxidative DNA damage generated in some special situations has been shown to synergistically induce cancer cell lethality with PARPis $[31-33,65,66]$. Here, we show that combining the PARPi olaparib with the highly tumorspecific DNA damaging agent, ATL, results in synergistic lethality at nontoxic doses of both drugs. The combination exploits a cancer vulnerability driven by the high levels of intrinsic oxidative pressure in cancer cells. Normal tissues are spared due to their lower basal ROS output. As high oxidative pressure is a universal feature of tumors, both primary and relapsed, our findings may open new routes to broaden the therapeutic potential of PARP inhibitors.

\section{Materials and methods}

\section{Cell line and cell culture}

The SW480, A549, PC-3, and 293T cell lines were purchased from the American Type Culture Collection (ATCC, Manassas, VA, USA), BEAS-2B, NCM460 and all other cell lines were obtained from the Cell Bank of the Chinese Academy of Sciences (Shanghai, China). All cell lines were authenticated by STR profiling, routinely tested for mycoplasma, and maintained at $37^{\circ} \mathrm{C}$ in a humidified incubator in $5 \% \mathrm{CO}_{2}$.

\section{Materials}

Olaparib (AZD2281, S1060), veliparib (ABT-888, S-1004), Z-VAD-FMK (S7023), and cisplatin (S1166) were purchased from Selleck (Houston, TX, USA). The OGG1 inhibitor O8 (SML1697), doxycycline (D1822), 5-chloro2'-deoxyuridine (CIdU) (C6891), PEG 300 (90878) and $\mathrm{N}$ acetyl-L-cysteine (NAC) (BP907) were purchased from Sigma-Aldrich (St. Louis, MO, USA). Alantolactone (B21267) was bought from Yuanye (Shanghai, China), idoxuridine (IdU) (HY-B0307) from MCE (Monmouth Junction, NJ, USA), auranofin (B7678) from APExBIO (Houston, TX, USA) and aphidicolin (ab142400) from Abcam (Cambridge, UK). Stock solutions of ATL and olaparib were made in 100\% dimethyl sulfoxide (DMSO) (Sigma-Aldrich) and working solutions were prepared in complete cell culture medium. The solution with the same concentration of DMSO but without the test compound was used as vehicle control. Primary antibodies include $\gamma \mathrm{H} 2 \mathrm{AX}$ pS139 polyclonal antibody (ab11174), poly(ADP-ribose) polymer (ab14459), and BrdU (ab6326, ab8152) (Abcam); cleaved caspase-3 (9664S), H3-pS10 (9706L), CHK1pS317 (12302S), and CHK2-pT68 (2661S) (Cell Signaling, Danvers, MA, USA); RPA32 (bs-4182R), CHK1 (bs1681R), OGG1 (bs3687R), GAPDH (bs10900R), and $\beta$-actin (bsm33036M) (Bioss, Beijing, China); H3 (abs131869), H2AX (abs131731), CHK2 (abs131635) (Absin Bioscience, Shanghai, China); RPA32-pS4/8 
(NBP1-23017) (NOVUS, Centennial, CO, USA), 53BP1 (A300-272A) (Bethyl, Montgomery, TX, USA), $\gamma \mathrm{H} 2 \mathrm{AX}-$ pS139 monoclonal antibody (14-9865-82) (ThermoFisher, Waltham, MA, USA). Secondary antibodies include goat anti-mouse-Alexa 488, goat anti-rabbit-Cy3, goat anti-ratAlexa-488, goat anti-mouse-horseradish peroxidase and goat anti-rabbit-horseradish peroxidase (Jackson ImmunoResearch, West Grove, PA, USA).

\section{Cell viability assay}

Cells were seeded in 96-well plates and at the end of drug treatment, $20 \mu \mathrm{l}$ of $5 \mathrm{mg} / \mathrm{ml}$ 3-(4,5-dimethylthiazol-2-yl)2,5-diphenyl tetrazolium bromide (MTT) (Sigma-Aldrich) was added to each well. The plates were incubated for $4 \mathrm{~h}$ at $37^{\circ} \mathrm{C}$ and $100 \mu$ of DMSO was added to each well. The plate was left on a plate shaker for $30 \mathrm{~min}$ with gentle shaking at room temperature. The absorbance of each well was measured at $595 \mathrm{~nm}$.

\section{Colony formation assay}

Cells were seeded into 12 -well plates at 500 cells/well. Starting from the second day, cells were treated with drug for 7 days and then stained with crystal violet, dissolved in $70 \%$ ethanol and absorbance at $595 \mathrm{~nm}$ was obtained.

\section{Immunofluorescence microscopy}

For detection of chromatin-bound RPA foci, cells were incubated in pre-extraction buffer $(100 \mathrm{mM} \mathrm{NaCl}, 300 \mathrm{mM}$ sucrose, $3 \mathrm{mM} \mathrm{MgCl}_{2}, 1 \mathrm{mM}$ EGTA, $0.2 \%$ Triton X-100 and $10 \mathrm{mM}$ PIPES, pH 6.8) for $5 \mathrm{~min}$; for Rad51 staining, cell monolayers were irradiated with 3 Gy X-rays delivered by the X-RAD 320ix biological irradiator or treated by $0.1 \mu \mathrm{M}$ cisplatin for $24 \mathrm{~h}$, followed by treatment with vehicle control, $10 \mu \mathrm{M}$ ATL or $10 \mu \mathrm{M}$ ATL combined with $10 \mu \mathrm{M}$ olaparib for the indicated lengths of time; to label DNA replicating cells, cultures were incubated in $10 \mu \mathrm{M}$ EdU for $20 \mathrm{~min}$ and processed with the Click-iT EdU Alexa Fluor 488 imaging kit (C0071S) (Beyotime Biotechnology, Shanhai, China). After the above treatments, cells were fixed in $4 \%$ paraformaldehyde for $20 \mathrm{~min}$ and then in ice-cold methanol:acetone for $20 \mathrm{~min}$ Subsequently, cells were blocked in PBST $(0.05 \%$ Tween- 20 in PBS) with $2 \%$ BSA for $1 \mathrm{~h}$, followed by incubation in primary and secondary antibodies. For immunostaining of 8-oxoG, fixed cells were incubated in Cy3-conjugated avidin [67] (Rockland Immunochemicals, Limerick, PA, USA) $(0.5 \mu \mathrm{g} / \mathrm{ml})$ for $1 \mathrm{~h}$ at room temperature. TUNEL staining was performed using the one-step TUNEL kit (Beyotime Biotechnology) according to instructions provided by the manufacturer.
Flow cytometry analysis of cell cycle and apoptosis

For cell cycle analysis, cells were fixed in $70 \%$ ethanol for $1 \mathrm{~h}$ at $-20^{\circ} \mathrm{C}$, treated with $100 \mu \mathrm{g} / \mathrm{ml}$ RNase A (SigmaAldrich) for $30 \mathrm{~min}$ at $37^{\circ} \mathrm{C}$ and stained with propidium iodide (100 $\mu \mathrm{g} / \mathrm{ml}$ in $1 \%$ sodium citrate) for $15 \mathrm{~min}$ in the dark. Cell cycle profiles were analyzed by the MoFlo XDP Cell Sorter (Beckman Coulter, Indianapolis, IN, USA) with the FlowJo software (FlowJo, Ashland, OR, USA). For analysis of apoptosis, cells were stained with Annexin VFITC and propidium iodide (PI) (Bestbio, Shanghai, Chain) at room temperature in the dark for $20 \mathrm{~min}$, analyzed by the MoFlo XDP Cell Sorter using the CytExpert software (Beckman Coulter).

\section{DR-GFP HR repair assay}

To establish stable cell lines harboring the DR-GFP gene cassette, the pDR-GFP plasmid (Addgene, \#26475) was transfected into PC-3 or A549 cells to get puromycinresistant clones. Next, $5 \mu \mathrm{g}$ of pCBAScel (Addgene, \#26477) and $1.5 \mu \mathrm{g}$ of pDsRed-N1 (Clontech, Mountain View, CA, USA) were co-transfected into the stable cell lines, and cells were treated with drugs or vehicle control for $12 \mathrm{~h}$.

\section{Measurement of cellular ROS}

Intracellular ROS levels were measured by flow cytometry using a cell-based ROS assay kit (S0033) (Beyotime Biotechnology). Cells grown in six-well plates were incubated with $10 \mu \mathrm{M}$ dichlorofluorescein diacetate (DCFH-DA) for $30 \mathrm{~min}$ at $37^{\circ} \mathrm{C}$ and analyzed by the MpFlo XDP Cell Sorter.

\section{Lentiviral shRNA knockdown}

PARP1 or OGG1 knockdown was achieved via transfection of cells with doxycycline inducible specific shRNA lentiviruses. The human PARP1 and OGG1-specific shRNA sequences were synthesized based on information validated by SigmaAldrich (PARP1: TRCN0000007929, TRCN0000007932; OGG1: TRCN0000314672, TRCN0000314739). These sequences were inserted into the pTet-pLKO-puro plasmid (Addgene, \#21915) and lentiviral particles were produced in 293 T cells transfected with the Tet-pLKO1-puro vector and the packaging vectors pMD2.G (Addgene, \#12259) and psPAX2 (Addgene, \#12260).

\section{Detection of chromatin-bound proteins}

After washing with PBS, cells were resuspended in $200 \mu \mathrm{l}$ of solution A $(10 \mathrm{mM}$ HEPES at $\mathrm{pH} 7.9,10 \mathrm{mM} \mathrm{KCl}$, 
$1.5 \mathrm{mM} \mathrm{MgCl} 2,0.34 \mathrm{M}$ sucrose, $10 \%$ glycerol, $1 \mathrm{mM}$ DTT, $10 \mathrm{mM} \mathrm{NaF}, 1 \mathrm{mM} \mathrm{Na} \mathrm{VO}_{3}$ and protease inhibitors). After adding Triton X-100 to a final concentration of $0.1 \%$, the cells were left on ice for $5 \mathrm{~min}$ and then centrifugated at $1400 \times g$ for $4 \mathrm{~min}$ to separate the cytoplasm from nuclei. The nuclei fraction was thoroughly washed with solution A and resuspended in $200 \mu \mathrm{l}$ of solution B ( $3 \mathrm{mM}$ EDTA, $0.2 \mathrm{mM}$ EGTA, $1 \mathrm{mM}$ DTT and protease inhibitors). After incubation at $4{ }^{\circ} \mathrm{C}$ for $30 \mathrm{~min}$, chromatin was separated from soluble nuclear substances by centrifugation at $1700 \times g$ for 4 min After washing three times with solution $B$, the chromatin fraction was collected by centrifugation at $1700 \times \mathrm{g}$ for $4 \mathrm{~min}$, resuspended in $200 \mu \mathrm{l}$ of PBS and sheared by sonication. Protein binding in the chromatin fraction was assessed by Western blot.

\section{Comet assay}

Five hundred cells were added to $1 \%$ low melting point agarose maintained $37^{\circ} \mathrm{C}$, laid on frosted slides (ThermoFisher) and froze at $4{ }^{\circ} \mathrm{C}$ for $20 \mathrm{~min}$ in the dark, followed by incubation in precooled lysis buffer $(2.5 \mathrm{M} \mathrm{NaCl}, 100 \mathrm{mM}$ EDTA, $10 \mathrm{mM}$ Tris- $\mathrm{HCl}$ and $1 \%$ sodium laurylsarcosine, pH 7.5 for neutral comet assay; pH 10.0 for alkaline comet assay) overnight. Triton X-100 was added to a final concentration of $1 \%$ before cooling. Slides were equilibrated for $20 \mathrm{~min}$ in precooled running buffer $(90 \mathrm{mM}$ Tris- $\mathrm{HCl}$, $90 \mathrm{mM}$ boric acid, $2 \mathrm{mM}$ EDTA, pH 7.5 for neutral comet assay; $300 \mathrm{mM} \mathrm{NaOH}, 1 \mathrm{mM}$ EDTA, $\mathrm{pH}>13$ for alkaline comet assay) and electrophoresis was run at $20 \mathrm{~V}$ for $30 \mathrm{~min}$ The slides were washed in neutralizing buffer (0.4 M TRIS, $\mathrm{pH}$ 7.5), placed in cold $70 \%$ ethanol for $5 \mathrm{~min}$, dried and stained with Vista Green DNA dye. The tail moment was defined as percentage of tail DNA $\times$ tail length, quantified using the TriTek CometScore sofware (TriTek Corp., Sumerduck, VA, USA).

\section{Pulse-labeling of DNA replication by CIdU and IdU}

Cells were labeled with $250 \mu \mathrm{M}$ CIdU for $30 \mathrm{~min}$, incubated in fresh medium with or without drug for $3 \mathrm{~h}$, followed by incubation in fresh medium containing $25 \mu \mathrm{M}$ IdU for $30 \mathrm{~min}$ The cells were fixed in methanol:acetone (3:1) for $15 \mathrm{~min}$, followed by blocking with 3\% BSA containing $0.03 \%$ Triton-X 100 for $30 \mathrm{~min}$ and incubation with primary and secondary antibodies.

\section{Tumor xenograft experiments}

All mouse studies followed the protocols approved by the Institutional Animal Care and Use Committee of Jilin University. PC-3 cell suspensions were prepared in 1:1 matrigel (CORNING, Corning, NY, USA) and $2 \times 10^{6}$ cells were inoculated subcutaneously into the left flanks of male athymic BALB/c nude mice (6-8 weeks old) (Charles River, Boston, MA, USA). Tumors were measured with calipers and the tumor volume was calculated according to the formula $V=1 / 2$ length $\times$ width $^{2}$. When the tumor volume reached approximately $150 \mathrm{~mm}^{3}$ (15 days after inoculation), mice were randomized into treatment and control groups ( $n=6$ each group) (no statistical methods were used to pre-determine sample size). The mice were treated once daily with $50 \mathrm{mg} / \mathrm{kg}$ ATL (1\% DMSO $+40 \%$ PEG 300) oral gavage (p.o.) or $50 \mathrm{mg} / \mathrm{kg}$ olaparib $(4 \%$ DMSO + 30\% PEG 300) intraperitoneal injection (i.p.) or combination of both for 15 days. Tumor volume and body weight were measured every three days, and tumor weight was measured at the end of the study. The investigators performing tumor measurements were blinded to the experimental design and the identity of treatment.

\section{Histology}

Heart, liver, and kidney tissues were fixed in $10 \%$ formalin, processed and embedded in paraffin. After deparaffinization and rehydration, $5 \mu \mathrm{m}$-thick sections were stained with hematoxylin solution for $5 \mathrm{~min}$, followed by five dips in $1 \%$ acid ethanol $(1 \% \mathrm{HCl}$ in $70 \%$ ethanol) and then rinsed in distilled water. The sections were then stained with eosin solution for $3 \mathrm{~min}$.

\section{Statistical analysis}

All data were presented as mean $\pm \mathrm{SD}$ of three independent experiments. Statistical comparisons were performed with the GraphPad Prism 7 software using the two-tailed Student's $t$-test. $p<0.05$ was considered to indicate a statistically significant difference.

Acknowledgements This work was supported by grants from the Key Research and Development Program of Jilin Province (20170204025YY) and the Natural Science Foundation of Jilin Province (20180101237JC).

\section{Compliance with ethical standards}

Conflict of interest The authors declare that they have no conflict of interest.

Publisher's note Springer Nature remains neutral with regard to jurisdictional claims in published maps and institutional affiliations.

Open Access This article is licensed under a Creative Commons Attribution 4.0 International License, which permits use, sharing, adaptation, distribution and reproduction in any medium or format, as long as you give appropriate credit to the original author(s) and the source, provide a link to the Creative Commons license, and indicate if changes were made. The images or other third party material in this article are included in the article's Creative Commons license, unless 
indicated otherwise in a credit line to the material. If material is not included in the article's Creative Commons license and your intended use is not permitted by statutory regulation or exceeds the permitted use, you will need to obtain permission directly from the copyright holder. To view a copy of this license, visit http://creativecommons. org/licenses/by/4.0/.

\section{References}

1. Pilié PG, Tang C, Mills GB, Yap TA. State-of-the-art strategies for targeting the DNA damage response in cancer. Nat Rev Clin Oncol. 2019;16:81-104.

2. Brown JS, O'Carrigan B, Jackson SP, Yap TA. Targeting DNA repair in cancer: beyond PARP inhibitors. Cancer Discov. 2017;7:20-37.

3. Ray Chaudhuri A, Nussenzweig A. The multifaceted roles of PARP1 in DNA repair and chromatin remodelling. Nat Rev Mol Cell Biol. 2017;18:610.

4. Hanzlikova H, Caldecott KW. Perspectives on PARPs in S phase. Trends Genet. 2019;35:412-22.

5. Abbotts R, Wilson DM 3rd. Coordination of DNA single strand break repair. Free Radic Biol Med. 2017;107:228-44.

6. Reynolds P, Cooper S, Lomax M, O'Neill P. Disruption of PARP1 function inhibits base excision repair of a sub-set of DNA lesions. Nucleic Acids Res. 2015;43:4028-38.

7. Yang YG, Cortes U, Patnaik S, Jasin M, Wang ZQ. Ablation of PARP-1 does not interfere with the repair of DNA double-strand breaks, but compromises the reactivation of stalled replication forks. Oncogene 2004;23:3872-82.

8. Bryant HE, Petermann E, Schultz N, Jemth AS, Loseva O, Issaeva $\mathrm{N}$, et al. PARP is activated at stalled forks to mediate Mre11dependent replication restart and recombination. EMBO J. 2009;28:2601-15.

9. Ronson GE, Piberger AL, Higgs MR, Olsen AL, Stewart GS, McHugh PJ, et al. PARP1 and PARP2 stabilise replication forks at base excision repair intermediates through Fbh1-dependent Rad51 regulation. Nat Commun. 2018;9:746.

10. Pommier Y, O'Connor M, de Bono J. Laying a trap to kill cancer cells: PARP inhibitors and their mechanisms of action. Sci Transl Med. 2016;8:362ps17.

11. Venkitaraman AR. Cancer suppression by the chromosome custodians, BRCA1 and BRCA2. Science. 2014;343:1470-75.

12. Bryant HE, Schultz N, Thomas HD, Parker KM, Flower D, Lopez E, et al. Specific killing of BRCA2-deficient tumours with inhibitors of poly(ADP-ribose) polymerase. Nature 2005;434:913-7.

13. Farmer H, McCabe N, Lord CJ, Tutt AN, Johnson DA, Richardson TB, et al. Targeting the DNA repair defect in BRCA mutant cells as a therapeutic strategy. Nature 2005;434:917-21.

14. Murai J, Huang SY, Das BB, Renaud A, Zhang Y, Doroshow JH, et al. Trapping of PARP1 and PARP2 by clinical PARP inhibitors. Cancer Res 2012;72:5588-99.

15. Lord CJ, Ashworth A. PARP inhibitors: synthetic lethality in the clinic. Science 2017;355:1152-58.

16. Yap TA, Plummer R, Azad NS, Helleday T. The DNA damaging revolution: PARP inhibitors and beyond. Am Soc Clin Oncol Educ Book. 2019;39:185-95.

17. Trucco C, Javier Oliver F, de Murcia G, Ménissier-de Murcia J. DNA repair defect in poly(ADP-ribose) polymerase-deficient cell lines. Nucleic Acids Res. 1998;26:2644-49.

18. Menissier de Murcia J, Ricoul M, Tartier L, Niedergang C, Huber A, Dantzer F, et al. Functional interaction between PARP-1 and PARP-2 in chromosome stability and embryonic development in mouse. EMBO J. 2003;22:2255-63.
19. Sarkaria JN, Kitange GJ, James CD, Plummer R, Calvert H, Weller M, et al. Mechanisms of chemoresistance to alkylating agents in malignant glioma. Clin Cancer Res. 2008;14:2900-08.

20. Michels J, Vitale I, Galluzzi L, Adam J, Olaussen KA, Kepp O, et al. Cisplatin resistance associated with PARP hyperactivation. Cancer Res 2013;73:2271-80.

21. PG P, CM G, LA B, MJ OC, TA Y. PARP inhibitors: extending benefit beyond-mutant cancers. Clin Cancer Res. 2019;25:3759-71.

22. Murai J, Zhang Y, Morris J, Ji J, Takeda S, Doroshow JH, et al. Rationale for poly(ADP-ribose) polymerase (PARP) inhibitors in combination therapy with camptothecins or temozolomide based on PARP trapping versus catalytic inhibition. J Pharmacol Exp Ther. 2014;349:408-16.

23. Saikolappan S, Kumar B, Shishodia G, Koul S, Koul HK. Reactive oxygen species and cancer: a complex interaction. Cancer Lett 2019;452:132-43.

24. Trachootham D, Zhou Y, Zhang H, Demizu Y, Chen Z, Pelicano $\mathrm{H}$, et al. Selective killing of oncogenically transformed cells through a ROS-mediated mechanism by beta-phenylethyl isothiocyanate. Cancer Cell 2006;10:241-52.

25. Gorrini C, Harris IS, Mak TW. Modulation of oxidative stress as an anticancer strategy. Nat Rev Drug Discov. 2013;12:931-47.

26. Harris IS, Treloar AE, Inoue S, Sasaki M, Gorrini C, Lee KC, et al. Glutathione and thioredoxin antioxidant pathways synergize to drive cancer initiation and progression. Cancer Cell 2015;27:211-22.

27. AbdulSalam SF, Thowfeik FS, Merino EJ. Excessive reactive oxygen species and exotic DNA lesions as an exploitable liability. Biochemistry 2016;55:5341-52.

28. El-Khamisy SF, Masutani M, Suzuki H, Caldecott KW. A requirement for PARP-1 for the assembly or stability of XRCC1 nuclear foci at sites of oxidative DNA damage. Nucleic Acids Res. 2003;31:5526-33.

29. BC W, JL P, GL D. Poly(ADP-ribose) polymerase-1 modulates DNA repair capacity and prevents formation of DNA double strand breaks. DNA Repair. 2008;7:932-40.

30. Hsu PC, Gopinath RK, Hsueh YA, Shieh SY. CHK2-mediated regulation of PARP1 in oxidative DNA damage response. Oncogene 2019;38:1166-82.

31. Deben C, Lardon F, Wouters A, Op de Beeck K, Van den Bossche J, Jacobs J, et al. APR-246 (PRIMA-1(MET)) strongly synergizes with AZD2281 (olaparib) induced PARP inhibition to induce apoptosis in non-small cell lung cancer cell lines. Cancer Lett 2016;375:313-22.

32. Huang X, Motea EA, Moore ZR, Yao J, Dong Y, Chakrabarti G, et al. Leveraging an NQO1 bioactivatable drug for tumor-selective use of poly(ADP-ribose) polymerase Inhibitors. Cancer Cell 2016;30:940-52.

33. Liu Q, Gheorghiu L, Drumm M, Clayman R, Eidelman A, Wszolek MF, et al. PARP-1 inhibition with or without ionizing radiation confers reactive oxygen species-mediated cytotoxicity preferentially to cancer cells with mutant TP53. Oncogene 2018;37:2793-805.

34. Zhang J, Li Y, Duan D, Yao J, Gao K, Fang J. Inhibition of thioredoxin reductase by alantolactone prompts oxidative stress-mediated apoptosis of HeLa cells. Biochemical Pharmacol 2016;102:34-44.

35. Yin C, Dai X, Huang X, Zhu W, Chen X, Zhou Q, et al. Alantolactone promotes ER stress-mediated apoptosis by inhibition of TrxR1 in triple-negative breast cancer cell lines and in a mouse model. J Cell Mol Med. 2019;23:2194-206.

36. He W, Cao P, Xia Y, Hong L, Zhang T, Shen X, et al. Potent inhibition of gastric cancer cells by a natural compound via inhibiting TrxR1 activity and activating ROS-mediated p38 MAPK pathway. Free Radic Res. 2019;53:104-14. 
37. Xu X, Huang L, Zhang Z, Tong J, Mi J, Wu Y, et al. Targeting non-oncogene ROS pathway by alantolactone in B cell acute lymphoblastic leukemia cells. Life Sci 2019;227:153-65.

38. Ding Y, Wang H, Niu J, Luo M, Gou Y, Miao L, et al. Induction of ROS overload by alantolactone prompts oxidative DNA damage and apoptosis in colorectal cancer cells. Int J Mol Sci. 2016;17:558.

39. Zhao P, Pan Z, Luo Y, Zhang L, Li X, Zhang G, et al. Alantolactone induces apoptosis and cell cycle arrest on lung squamous cancer SKMES-1 cells. J Biochem Mol Toxicol. 2015;29:199-206.

40. Liu J, Liu M, Wang S, He Y, Huo Y, Yang Z, et al. Alantolactone induces apoptosis and suppresses migration in MCF7 human breast cancer cells via the p38 MAPK, NFkappaB and Nrf2 signaling pathways. Int J Mol Med. 2018;42:1847-56.

41. Davalli P, Marverti G, Lauriola A, D'Arca D. Targeting oxidatively induced DNA damage response in cancer: opportunities for novel cancer therapies. Oxid Med Cell Longev. 2018;2018:2389523.

42. Markkanen E. Not breathing is not an option: How to deal with oxidative DNA damage. DNA Repair. 2017;59:82-105.

43. Chou T-C. The combination index $(\mathrm{CI}<1)$ as the definition of synergism and of synergy claims. Synergy. 2018;7:49-50.

44. Lord CJ, Ashworth A. BRCAness revisited. Nat Rev Cancer. 2016;16:110-20.

45. Konstantinopoulos PA, Ceccaldi R, Shapiro GI, D'Andrea AD. Homologous recombination deficiency: exploiting the fundamental vulnerability of ovarian cancer. Cancer Discov 2015;5:1137-54.

46. Graeser M, McCarthy A, Lord CJ, Savage K, Hills M, Salter J, et al. A marker of homologous recombination predicts pathologic complete response to neoadjuvant chemotherapy in primary breast cancer. Clin Cancer Res. 2010;16:6159-68.

47. Pierce AJ, Johnson RD, Thompson LH, Jasin M. XRCC3 promotes homology-directed repair of DNA damage in mammalian cells. Genes Dev 1999;13:2633-38.

48. Elstrodt F, Hollestelle A, Nagel JH, Gorin M, Wasielewski M, van den Ouweland A, et al. BRCA1 mutation analysis of 41 human breast cancer cell lines reveals three new deleterious mutants. Cancer Res 2006;66:41-5.

49. Marzo T, Cirri D, Gabbiani C, Gamberi T, Magherini F, Pratesi A, et al. Auranofin, Et3PAuCl, and Et3PAuI are highly cytotoxic on colorectal cancer cells: a chemical and biological study. ACS Med Chem Lett. 2017;8:997-1001.

50. Ward IM, Chen J. Histone H2AX is phosphorylated in an ATRdependent manner in response to replicational stress. J Biol Chem. 2001;276:47759-62.

51. Burma S, Chen BP, Murphy M, Kurimasa A, Chen DJ. ATM phosphorylates histone H2AX in response to DNA double-strand breaks. J Biol Chem. 2001;276:42462-67.

52. Ciccia A, Elledge SJ. The DNA damage response: making it safe to play with knives. Mol Cell 2010;40:179-204.
53. Toledo LI, Altmeyer M, Rask MB, Lukas C, Larsen DH, Povlsen LK, et al. ATR prohibits replication catastrophe by preventing global exhaustion of RPA. Cell 2013;155:1088-103.

54. Schultz LB, Chehab NH, Malikzay A, Halazonetis TD. p53 binding protein $1(53 \mathrm{BP} 1)$ is an early participant in the cellular response to DNA double-strand breaks. J Cell Biol. 2000;151:1381-90.

55. Hans F, Dimitrov S. Histone H3 phosphorylation and cell division. Oncogene 2001;20:3021-27.

56. Nickoloff JA, Jones D, Lee SH, Williamson EA, Hromas R. Drugging the cancers addicted to DNA repair. J Natl Cancer Inst. 2017;109:djx059.

57. Piskounova E, Agathocleous M, Murphy MM, Hu Z, Huddlestun SE, Zhao Z, et al. Oxidative stress inhibits distant metastasis by human melanoma cells. Nature 2015;527:186-91.

58. Moloney JN, Cotter TG. ROS signalling in the biology of cancer. Semin Cell Dev Biol. 2018;80:50-64.

59. Sayin VI, Ibrahim MX, Larsson E, Nilsson JA, Lindahl P, Bergo MO. Antioxidants accelerate lung cancer progression in mice. Sci Transl Med. 2014;6:221ra15.

60. Le Gal K, Ibrahim MX, Wiel C, Sayin VI, Akula MK, Karlsson C, et al. Antioxidants can increase melanoma metastasis in mice. Sci Transl Med. 2015;7:308re8.

61. Rojo de la Vega M, Chapman E, Zhang DD. NRF2 and the Hallmarks of cancer. Cancer cell 2018;34:21-43.

62. Wang K, Jiang J, Lei Y, Zhou S, Wei Y, Huang C. Targeting metabolic-redox circuits for cancer therapy. Trends Biochem Sci. 2019;44:401-14.

63. Zhou B, Ye J, Yang N, Chen L, Zhuo Z, Mao L, et al. Metabolism and pharmacokinetics of alantolactone and isoalantolactone in rats: thiol conjugation as a potential metabolic pathway. J Chromatogr B. 2018;1072:370-78.

64. Lee JY, Kim SB, Chun J, Song KH, Kim YS, Chung SJ, et al. High body clearance and low oral bioavailability of alantolactone, isolated from Inula helenium, in rats: extensive hepatic metabolism and low stability in gastrointestinal fluids. Biopharm Drug Dispos. 2016;37:156-67.

65. Marcar L, Bardhan K, Gheorghiu L, Dinkelborg P, Pfäffle H, Liu $\mathrm{Q}$, et al. Acquired resistance of EGFR-mutated lung cancer to tyrosine kinase inhibitor treatment promotes PARP inhibitor sensitivity. Cell Rep. 2019;27:3422-32.e4.

66. Pulliam N, Fang F, Ozes AR, Tang J, Adewuyi A, Keer H, et al. An effective epigenetic-PARP inhibitor combination therapy for breast and ovarian cancers independent of BRCA mutations. Clin Cancer Res. 2018;24:3163-75.

67. Struthers L, Patel R, Clark J, Thomas S. Direct detection of 8oxodeoxyguanosine and 8-oxoguanine by avidin and its analogues. Anal Biochem. 1998;255:20-31. 